\title{
Article \\ The Effects of the Binder and Buffering Matrix on InSb-Based Anodes for High-Performance Rechargeable Li-Ion Batteries
}

\author{
Vo Pham Hoang Huy, Il Tae Kim *(D) and Jaehyun Hur * (D) \\ Department of Chemical and Biological Engineering, Gachon University, Seongnam 13120, Gyeonggi, Korea; \\ vophamhoanghuy@yahoo.com.vn \\ * Correspondence: itkim@gachon.ac.kr (I.T.K.); jhhur@gachon.ac.kr (J.H.); \\ Tel.: +82-31-750-8835 (I.T.K.); +82-31-750-5593 (J.H.)
}

Citation: Hoang Huy, V.P.; Kim, I.T.; Hur, J. The Effects of the Binder and Buffering Matrix on InSb-Based Anodes for High-Performance Rechargeable Li-Ion Batteries. Nanomaterials 2021, 11, 3420. https:// doi.org/10.3390/nano11123420

Academic Editor: Carlos Miguel Costa

Received: 25 November 2021 Accepted: 15 December 2021 Published: 17 December 2021

Publisher's Note: MDPI stays neutral with regard to jurisdictional claims in published maps and institutional affiliations.

Copyright: (c) 2021 by the authors. Licensee MDPI, Basel, Switzerland. This article is an open access article distributed under the terms and conditions of the Creative Commons Attribution (CC BY) license (https:// creativecommons.org/licenses/by/ $4.0 /)$.

\begin{abstract}
C-decorated intermetallic InSb (InSb-C) was developed as a novel high-performance anode material for lithium-ion batteries (LIBs). InSb nanoparticles synthesized via a mechanochemical reaction were characterized using X-ray diffraction (XRD), high-resolution transmission electron microscopy (HRTEM), scanning electron microscopy (SEM), X-ray photoelectron spectroscopy (XPS), and energy-dispersive X-ray spectroscopy (EDX). The effects of the binder and buffering matrix on the active InSb were investigated. Poly(acrylic acid) (PAA) was found to significantly improve the cycling stability owing to its strong hydrogen bonding. The addition of amorphous $\mathrm{C}$ to $\mathrm{InSb}$ further enhanced mechanical stability and electronic conductivity. As a result, InSb-C demonstrated good electrochemical Li-ion storage performance: a high reversible specific capacity $\left(878 \mathrm{mAh} \cdot \mathrm{g}^{-1}\right.$ at $100 \mathrm{~mA} \cdot \mathrm{g}^{-1}$ after 140 cycles) and good rate capability (capacity retention of $98 \%$ at $10 \mathrm{~A} \cdot \mathrm{g}^{-1}$ as compared to $0.1 \mathrm{~A} \cdot \mathrm{g}^{-1}$ ). The effects of PAA and C were comprehensively studied using cyclic voltammetry, differential capacity plots, ex-situ SEM, and electrochemical impedance spectroscopy (EIS). In addition, the electrochemical reaction mechanism of InSb was revealed using ex-situ XRD. $\mathrm{InSb}-\mathrm{C}$ exhibited a better performance than many recently reported Sb-based electrodes; thus, it can be considered as a potential anode material in LIBs.
\end{abstract}

Keywords: InSb; InSb-C; PAA binder; anodes; Li-ion batteries

\section{Introduction}

Lithium-ion batteries (LIBs) have been widely used in various portable devices and energy storage systems owing to their high energy density, high cell voltage, low selfdischarge, and low memory effect [1-4]. Despite these beneficial features, current graphite anodes cannot satisfy the rapidly growing demands for their use in various applications, such as mobile devices, electrical vehicles, and large-scale grid storage systems. Therefore, the development of new anode materials with a high specific capacity, good rate capability, and long service life that can replace low theoretical capacity $\left(372 \mathrm{mAh} \cdot \mathrm{g}^{-1}\right)$ commercial graphitic anodes is required [4-17]. Li alloys with elements, such as Si, P, Sn, and Sb, are considered to be promising anode materials because of their higher theoretical capacities (Si: 4200, P: 2595, Sn: 993, and Sb: $660 \mathrm{mAh} \cdot \mathrm{g}^{-1}$ ). However, it is not straightforward to control the large volume change in these materials due to expansion/contraction during lithiation/delithiation, which leads to a deteriorated cell performance [18-23].

Recently, Sb-based materials have gained significant attention as promising anodes in LIBs owing to their low cost, high conductivity, high density, and high theoretical capacity [24-27]. Sb has higher conductivity and stability than P (the same element family) and Si (the material with the highest theoretical capacity), making it a suitable material for the development of high-performance anodes for LIBs. Because of these attractive characteristics, $\mathrm{Sb}$ has been intensively investigated for use in LIBs. However, satisfactory performance cannot be achieved using $\mathrm{Sb}$ alone because of its high-volume expansion 
(135\%) during the alloying reaction $\left(3 \mathrm{Li}^{+}+\mathrm{Sb} \rightarrow \mathrm{Li}_{3} \mathrm{Sb}\right)$ [28]. Many strategies have been proposed to resolve this problem.

The formation of a nanoscale Sb-based intermetallic alloy is an effective approach that can improve the cycling stability of $\mathrm{Sb}$-based electrodes. Nanoscale active materials reduce the Li-ion diffusion pathway and alleviate the stress and strain during the electrochemical reaction. In addition, the stepwise electrochemical reaction in bimetallic Sb-based alloy nanoparticles can mitigate a large volume change relative to a pure $\mathrm{Sb}$ electrode. Along this line, He et al. demonstrated monodisperse colloidal $\mathrm{SnSb}$ nanocrystals (approximately $20 \mathrm{~nm}$ ) with a discharge capacity of $700 \mathrm{mAh} \cdot \mathrm{g}^{-1}$ at $0.5 \mathrm{C}$ after 100 cycles [29]. Yi et al. synthesized morphology-controllable $\mathrm{Sn}-\mathrm{Sb}$ composites with micro- and nano-sized hollow, dendritic, or mixed-type structures; these designed composites also exhibited good cycling stability and rate performance in LIBs and sodium-ion batteries (SIBs) [29].

Another effective approach that can enhance the performance of Sb-based electrodes is to introduce various nanoscale conductive carbon materials to create nanostructured $\mathrm{Sb} / \mathrm{C}$ composites (e.g., 1D carbon nanotubes, nanofibers, nanorods, 2D graphene, 3D graphite, and porous carbon) [30-33]. In this composite, carbon prevents the agglomeration of nanoparticles, increases the electrical conductivity, and reduces the volume change of the active $\mathrm{Sb}$ [34-36]. Therefore, the cycling stability is notably improved by adding carbon.

The binder is the crucial adhesive between the active material and conductive carbon on the current collector. The adhesion between the active component and the binder is very important during the electrochemical reaction because the stress on the active material caused by volume expansion can weaken the binding force. In a pioneering study on binder materials, Kim et al. studied the effect of a new binder material (a blend of poly(acrylic acid) (PAA) and poly(amide imide) (PAI)) on electrode adhesion and recovery characteristics. They demonstrated that the composite polymer binder exhibited superior properties compared to the individual polymers [37]. Similarly, Choi et al. developed a new polyrotaxane-based binder for active micro-silicon particle batteries in which they achieved a remarkably stable capacity of over $3000 \mathrm{mAh} \cdot \mathrm{g}^{-1}$ after 150 cycles [38]. Wu et al. have shown that conductive binders based on polyfluorene (PF) exhibit superior performance owing to their electronic conductivity and mechanical strength [39]. Among the various binders studied, PAA has shown exceptionally good performance for the Si electrode because of (i) its abundant carboxylic acid functional groups $(-\mathrm{COOH})$ that enable strong bonding to the native hydroxyl species on the Si particle surface [40,41]; (ii) good mechanical strength associated with low swelling in a liquid electrolyte [42]; and (iii) the formation of an artificial solid electrolyte interface (SEI) on the Si surface that stabilizes the electrode-electrolyte interface [43]. Accordingly, PAA is expected to be a promising binder for various anode materials with a large volume change in LIBs.

In this study, we demonstrate $\mathrm{C}$-decorated $\mathrm{InSb}(\mathrm{InSb}-\mathrm{C})$ as a novel $\mathrm{Sb}$-based bimetallic high-performance anode for LIBs. InSb has been widely studied for use in transistors, magnetic sensors, and infrared photodetectors because of its semiconducting properties, which include a narrow band gap $(0.17 \mathrm{eV})$, high electron mobility, and a high density of conduction states [44-46]. Although some In-based nanomaterials have been reported as good anode materials owing to the high theoretical capacity of In $\left(1012 \mathrm{mAh} \cdot \mathrm{g}^{-1}\right)$ [27,28], intermetallic InSb has rarely been investigated as an anode material for LIBs. To achieve a high-performance InSb electrode, we investigate the effects of the binder and buffering matrix on the performance of InSb. This study demonstrates that PAA is an effective binder that impedes volume expansion and limits the structural degradation of the electrode owing to its strong hydrogen bonding with the active InSb. The addition of amorphous $\mathrm{C}$ reduces the stresses in InSb during lithiation/delithiation and increases the electrical conductivity. Therefore, with an appropriate binder and matrix, InSb-C exhibits high performance in terms of specific capacity, cyclic stability, and rate performance. Various characterization techniques are used to elucidate the mechanism behind the improvement, including X-ray diffraction (XRD), scanning electron microscopy (SEM), high-resolution transmission electron microscopy (HRTEM), energy-dispersive X-ray spectroscopy (EDX), 
Fourier-transform infrared spectroscopy (FTIR), X-ray photoelectron spectroscopy (XPS), and electrochemical impedance spectroscopy (EIS). Furthermore, the phase transformation mechanism of InSb during lithiation/delithiation is studied using ex-situ XRD.

\section{Experimental Section}

\subsection{Synthesis of InSb and InSb-C}

InSb was synthesized using high-energy mechanical milling (HEMM). In (99.99\%, Sigma-Aldrich, St. Louis, MO, USA) and Sb (99.998\%, Sigma-Aldrich, St. Louis, MO, USA) powders were mixed in a 1:1 molar ratio and then placed in an $80 \mathrm{~cm}^{3} \mathrm{ZrO}_{2}$ bowl with hardened $\mathrm{ZrO}_{2}$ balls in a 20:1 ball-to-powder ratio. The mixture was milled in an $\mathrm{Ar}$ atmosphere for $10 \mathrm{~h}$ at $300 \mathrm{rpm}$. InSb-C nanocomposites were prepared using HEMM, where a mixture of as-synthesized InSb and acetylene black powder $(99.9 \%, 100 \%$ compressed, specific surface area of $75 \mathrm{~m}^{2} \cdot \mathrm{g}^{-1}$, bulk density of $170-230 \mathrm{~g} \cdot \mathrm{L}^{-1}$, Alfa Aesar, Catalog No. 045527, Ward Hill, MA, USA) at a mass ratio of 9:1 was milled under the same conditions as the InSb synthesis. The mechanochemical synthesis reaction for $\mathrm{InSb}-\mathrm{C}$ is described as follows:

$$
\mathrm{In}+\mathrm{Sb} \rightarrow \mathrm{InSb}+\mathrm{C} \rightarrow \mathrm{InSb}-\mathrm{C}
$$

\subsection{Material Characterization}

The crystal structures of the as-prepared InSb and InSb-C were measured using powder XRD (D/MAX-2200 Rigaku, Tokyo, Japan) with $\mathrm{Cu} K \alpha(\lambda=1.54 \AA)$ radiation. The microscopic morphology of the as-synthesized powder materials was observed using HRTEM (JEOL JEM-2100F) and SEM (Hitachi S4700, Tokyo, Japan). XPS (Kratos Axis Anova, Manchester, UK) was used to evaluate the chemical states of the synthesized materials. The elemental content and distribution of the as-prepared powder and electrode after electrochemical reactions were evaluated using EDX.

\subsection{Electrochemical Measurements}

All electrodes were prepared by casting a slurry containing $70 \%$ active material, $15 \%$ carbon (Super-P, 99.9\%, Alfa Aesar), and 15\% PAA (Mw 450000, Sigma Aldrich, St. Louis, MO, USA) or a poly(vinylidene fluoride) (PVDF, MW 534000, Sigma Aldrich, St. Louis, $\mathrm{MO}, \mathrm{USA}$ ) binder dissolved in N-Methyl-2-pyrrolidone. The cast electrodes were dried overnight in a vacuum oven at $70{ }^{\circ} \mathrm{C}$ and then transferred to an Ar glove box for cell assembly. A coin-type cell (CR2032) was used for half-cell testing. Li metal foil and polyethylene were used as the counter electrode and separating membrane, respectively. The electrolyte was $1 \mathrm{M} \mathrm{LiPF}_{6}$ in ethylene carbonate/diethyl carbonate (EC/DEC, 1:1 v/v). The electrochemical performance of InSb and InSb-C was evaluated using a battery testing system (WBCS3000, WonATech, Seoul, South Korea). The galvanostatic charge-discharge (GCD) profile was measured from 0.01 to $2.5 \mathrm{~V}\left(\mathrm{vs}\right.$. $\left.\mathrm{Li} / \mathrm{Li}^{+}\right)$. Cyclic voltammetry (CV) at a scanning rate of $0.1 \mathrm{mV} \cdot \mathrm{s}^{-1}$ was used to characterize the electrochemical reactions of InSb with $\mathrm{Li}^{+}$. The rate capability was measured using a battery cycler (WBCS3000, WonATech, Seoul, South Korea) at current densities of $0.1,0.5,1,3,5$, and $10 \mathrm{~A} \cdot \mathrm{g}^{-1}$. EIS (ZIVE MP1, WonATech) was measured in the frequency range from $100 \mathrm{kHz}$ to $100 \mathrm{mHz}$ with an AC amplitude of $10 \mathrm{mV}$.

\section{Results and Discussion}

Figure 1a shows the XRD pattern of the as-prepared InSb powder obtained using the HEMM process. The XRD pattern coincided with the standard data of zinc blende InSb (JCPDS \#06-0208) with no detected impurity phases. This indicated that a single phase of the zinc blende structure was successfully obtained, with a lattice constant of $0.646 \AA$ and a space group of $\mathrm{T}_{\mathrm{d}}{ }^{2}-\mathrm{F} 43 \mathrm{~m}$, as shown in the inset of Figure 1a. The average crystalline domain size of the as-prepared InSb was calculated to be $0.225 \mathrm{~nm}$ using the Scherrer formula (Table S1). The particle size of InSb ranged from hundreds of nanometers to a few 
micrometers (Figure $1 \mathrm{~b}, \mathrm{c}$ ). One of the most important factors affecting the cell performance and safety of LIBs as well as reducing cell aging is the particle size of the active material. The particle size of the material affects the electrochemical performance of the battery [47-49]. In general, the small particles have short diffusion pathways (fast Li-ion diffusion), large surface area, and lower overpotential, thus allowing faster C-rate operation and high capacity. However, the beneficial effect of particle size reduction on cell performance is limited to certain particle sizes. The excessively large surface area can lead to large proportion of passivation layers, such as SEI, leading to an irreversible capacity loss [50-52]. Considering this, commercial batteries usually contain micrometer-sized particles for the electrode materials. However, the appropriate size of electrode material highly depends on the intrinsic properties of the electrode materials because they have different atomic structures that influence the electrochemical kinetics, Li-ion intercalation capacities, and structural stability. The size of InSb particles (mostly 200-400 nm in Figure 1c) is thought to be effective in terms of Li-ion diffusion kinetics and capacity while restraining the excessive surface passivation (e.g., SEI). EDX analysis of the InSb powder revealed that the elemental ratio of In and $\mathrm{Sb}$ was approximately 1:1 (Figure $1 \mathrm{~d}$ ). The presence of $\mathrm{O}$ in the InSb powder is due to the partially oxidized surface of the InSb particles. The composition and chemical state of InSb were examined using XPS (Figure 1e,f). The XPS signals observed at 452.1 and $444.5 \mathrm{eV}$ (Figure 1e) can be ascribed to In $3 \mathrm{~d}_{3 / 2}$ and In $3 \mathrm{~d}_{5 / 2}$, respectively, while the peaks at 539.5 and $530.1 \mathrm{eV}$ (Figure $1 \mathrm{f}$ ) were indexed to $\mathrm{Sb} 3 \mathrm{~d}_{3 / 2}$ and $\mathrm{Sb} 3 \mathrm{~d}_{5 / 2}$, respectively, verifying the InSb alloy structure after the HEMM process. Meanwhile, the two small peaks at 536.9 and $527.2 \mathrm{eV}$ (Figure 1f) are related to the surface oxidation of the InSb materials, consistent with the EDX analysis results (Figure 1d). The FTIR analysis of the InSb also confirmed the presence of hydroxide functional groups, as shown in Figure S1. The presence of hydroxyl groups on InSb should result in a high affinity for binders with polar functional groups (such as PAA), which can form strong hydrogen bonds. The binder can then serve as an elastic barrier that prevents InSb particles from aggregating while maintaining stable contact between the electrode and current collector during electrochemical reactions.

The half-cell performance of InSb was measured using two different binders (PAA and PVDF) to investigate its electrochemical behavior (Figure 2). The GCD voltage profiles of InSb_PAA and InSb_PVDF are shown in Figure 2a and Figure S2, respectively. The initial charge/discharge capacities of InSb_PAA and InSb_PVDF were 790/635 and $770 / 643 \mathrm{mAh} \cdot \mathrm{g}^{-1}$, respectively, corresponding to initial coulombic efficiencies (ICEs) of $80.9 \%$ and $83.5 \%$. The irreversible capacity losses in the first cycle are associated with the formation of an SEI layer for both electrodes. Although the specific capacities of InSb were not significantly different for PAA and PVDF in the first cycle, a significant capacity reduction was observed for InSb_PVDF during the initial 10 cycles at both low (Figure 2b) and high current densities (Figure 2c). The specific capacities of InSb_PVDF were $203.3 \mathrm{mAh} \cdot \mathrm{g}^{-1}$ after 140 cycles and $146.8 \mathrm{mAh} \cdot \mathrm{g}^{-1}$ after 100 cycles at 100 and $500 \mathrm{~mA} \cdot \mathrm{g}^{-1}$, respectively, corresponding to capacity retention values of $30.4 \%$ and $27.5 \%$. Moreover, InSb_PAA displayed much better performance in terms of stability and capacity; it exhibited specific capacities of $639.5 \mathrm{mAh} \cdot \mathrm{g}^{-1}$ after 140 cycles (93.2\% capacity retention) and $558.3 \mathrm{mAh} \cdot \mathrm{g}^{-1}$ after 100 cycles ( $92.3 \%$ capacity retention) at 100 and $500 \mathrm{~mA} \cdot \mathrm{g}^{-1}$, respectively. Figure S3 displays the surface morphologies of pristine InSb_PAA and InSb_PVDF. InSb_PAA showed a more uniform surface with a lower roughness than InSb_PVDF owing to the strong hydrogen-bonding interaction between the hydroxyl groups on the InSb particles and the carboxylate groups in PAA, which is not present in InSb_PVDF. Figure $2 \mathrm{~d}$ shows the first five CV cycles for InSb_PAA in the voltage range from 0.005 to $3.0 \mathrm{~V}$ vs. $\mathrm{Li} / \mathrm{Li}^{+}$. The initial $\mathrm{CV}$ curve was markedly different from those of the subsequent cycles due to the formation of an SEI layer on the electrode surface. In the first discharge step, a significant reduction peak emerged at $0.38 \mathrm{~V}$, indicating the $\mathrm{Li}$ intercalation into $\mathrm{InSb}$ to form $\mathrm{Li}_{2} \mathrm{Sb}$ and $\mathrm{In}$. The peak emerging at $0.24 \mathrm{~V}$ can be due to the reaction between $\mathrm{In}$ and $\mathrm{Li}$ to form $\mathrm{Li}_{\mathrm{y}} \mathrm{In}$. Thus, after completing the discharge step, $\mathrm{Li}_{2} \mathrm{Sb}$ and $\mathrm{Li}_{2} \mathrm{In}$ appear as final products. In the charge process, three oxidation peaks were observed at voltages of $0.70,0.98$, and $1.12 \mathrm{~V}$. 
Among them, the first peak at $0.70 \mathrm{~V}$ corresponds to the complete exclusion of $\mathrm{Li}$, reverting $\mathrm{Li}_{2} \mathrm{In}$ into In. When the anode was charged to 0.98 and $1.12 \mathrm{~V}$, In began to intrude into $\mathrm{Li}_{2} \mathrm{Sb}$ to form InSb. The detailed analysis of this phase transformation will be discussed in the ex-situ analyses. However, the curves nearly overlapped after the second cycle, demonstrating the high reversibility and stability of InSb_PAA. Compared to InSb_PAA, InSb_PVDF showed relatively unstable CV curves with polarized oxidation and reduction peaks even after the second cycle (Figure S4).

(a)

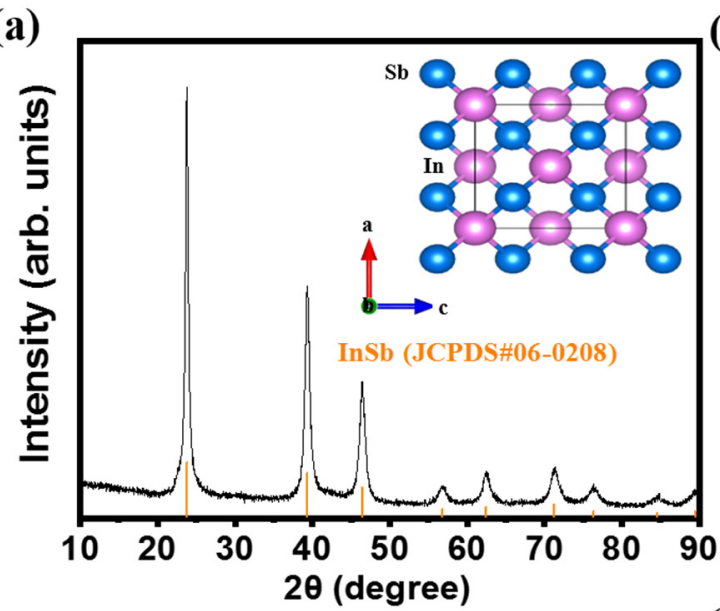

(c)

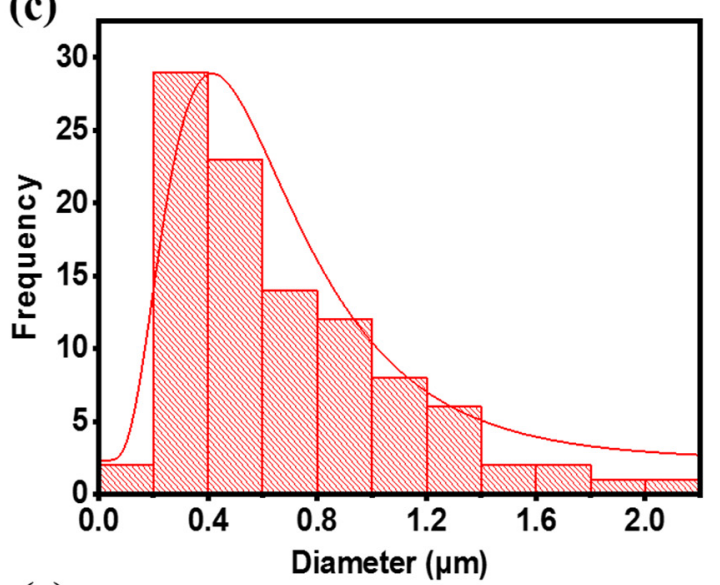

(e)

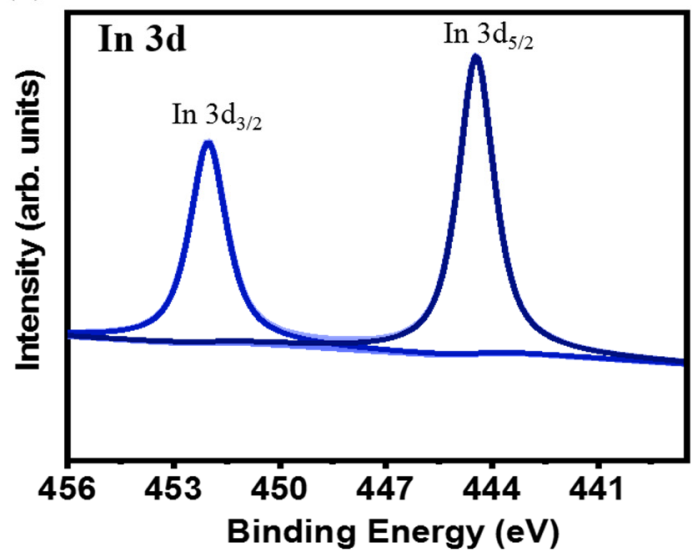

(b)

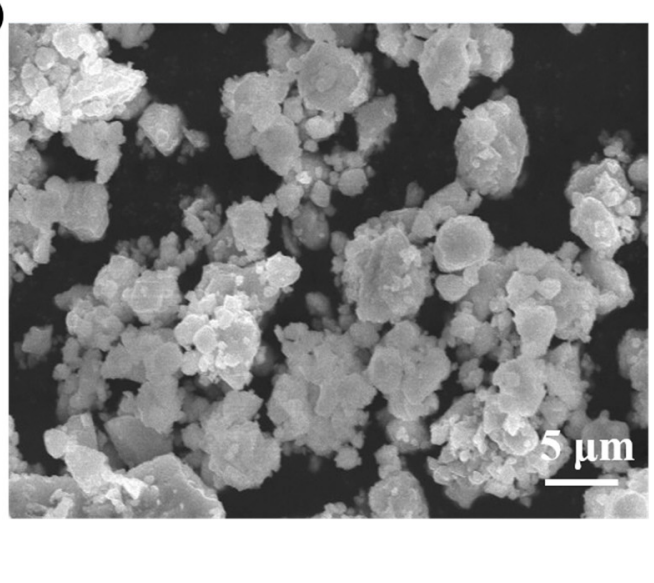

(d)

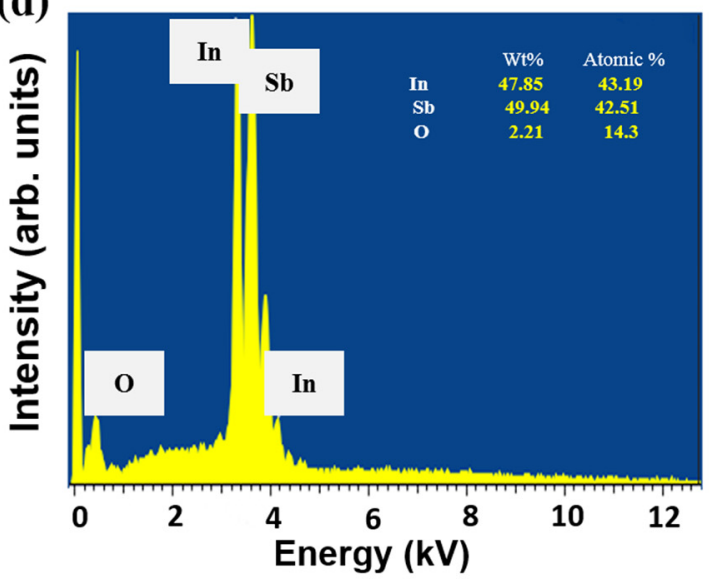

(f)

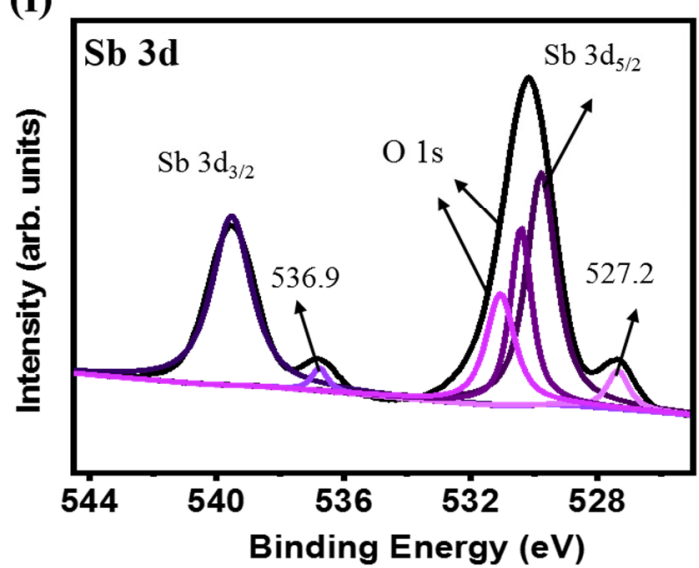

Figure 1. (a) XRD pattern (inset: crystalline structure), (b) SEM image, (c) particle size distribution, and (d) EDX spectrum of the as-synthesized InSb powder. XPS profiles of (e) In 3d, and (f) Sb 3d for the InSb powder. 
(a)

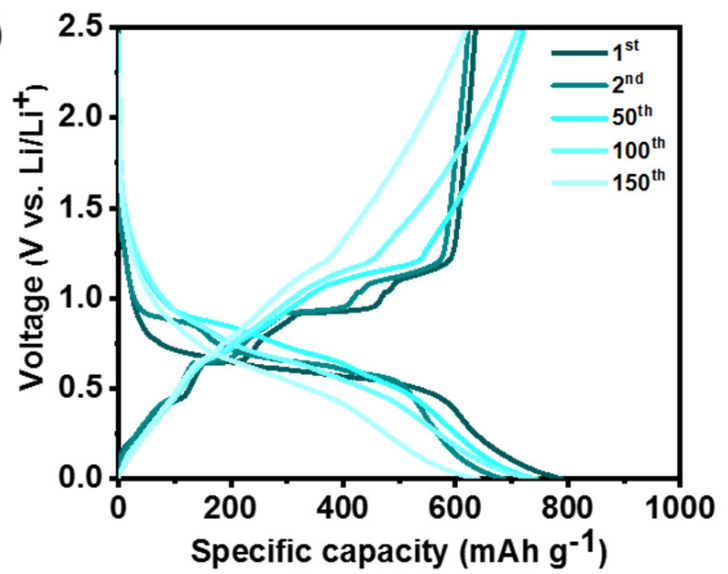

(c)

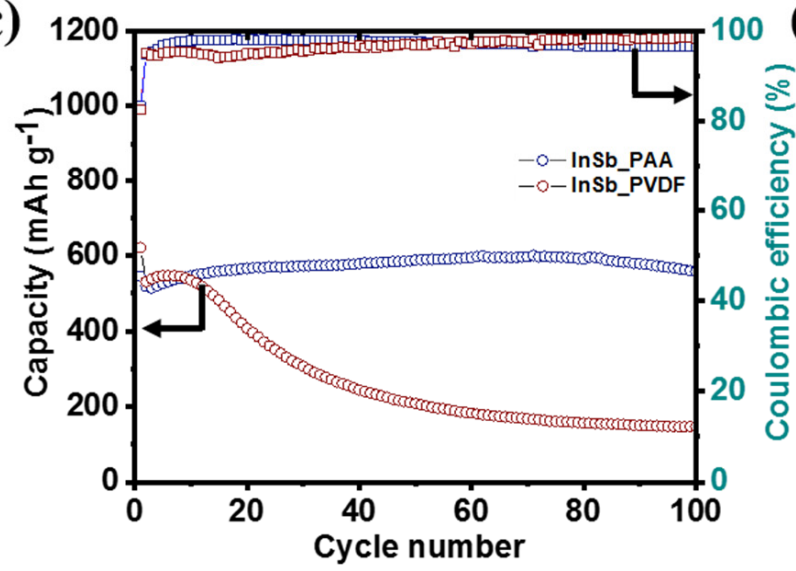

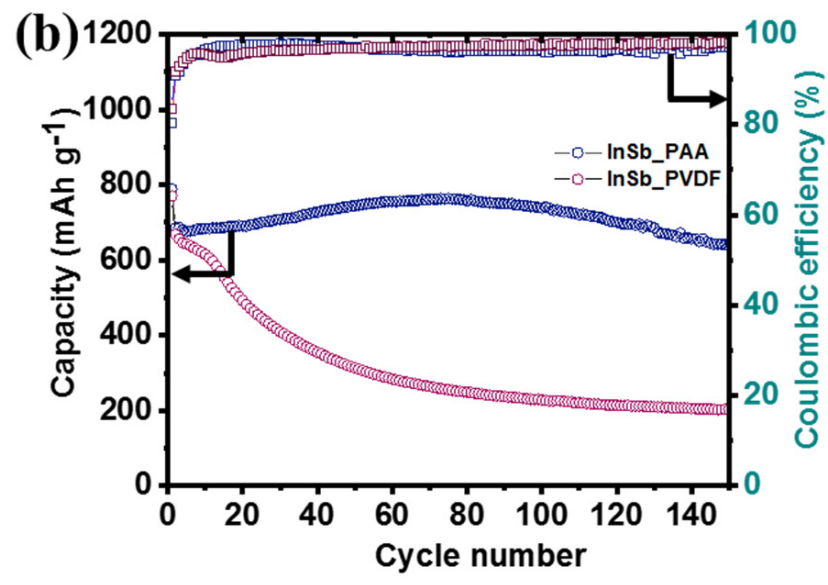

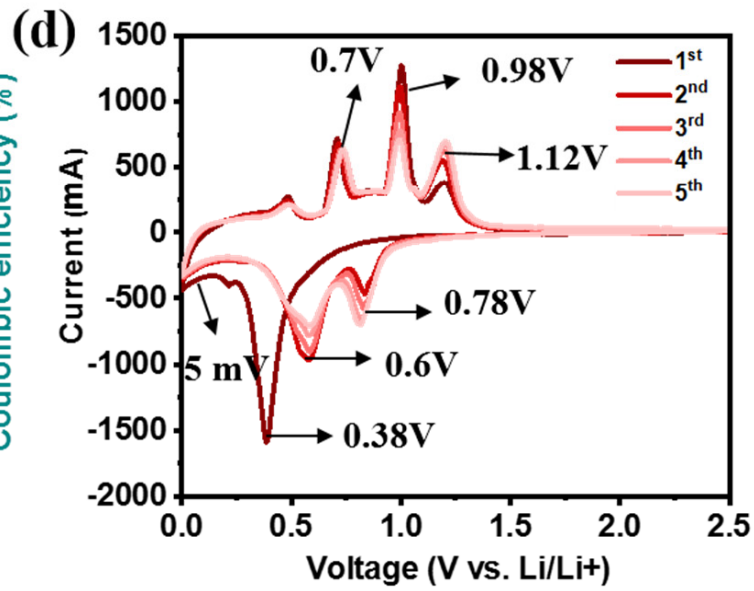

Figure 2. Electrochemical performance of the InSb electrode. (a) GCD voltage profiles of InSb_PAA at a current density of $100 \mathrm{~mA} \cdot \mathrm{g}^{-1}$. Cyclic performance of the InSb_PAA and InSb_PVDF at a current density of (b) 100 and (c) $500 \mathrm{~mA} \cdot \mathrm{g}^{-1}$. (d) CV curves of InSb_PAA.

Figure 3 compares the cross-sectional SEM images of InSb_PAA and InSb_PVDF in the pristine state and after 20 cycles. Although the thicknesses of InSb_PAA and InSb_PVDF were similar in the pristine states $(10.2 \mu \mathrm{m}$ in Figure $3 \mathrm{a}, \mathrm{d})$, InSb_PAA was thinner $(10.8 \mu \mathrm{m}$ in Figure 3b) than InSb_PVDF (12.4 $\mu \mathrm{m}$ in Figure 3e) after 20 cycles, indicating a smaller volume expansion of the InSb_PAA. In addition, the InSb_PAA maintained close contact between the electrode and current collector after 20 cycles (Figure 3c). However, the InSb_PVDF electrode partially delaminated from the current collector (Figure 3e) and aggregated (Figure 3f), because it failed to accommodate the large volume change of the InSb particles during repeated electrochemical reactions. These results justify the selection of PAA as an appropriate binder material for the InSb electrode. 

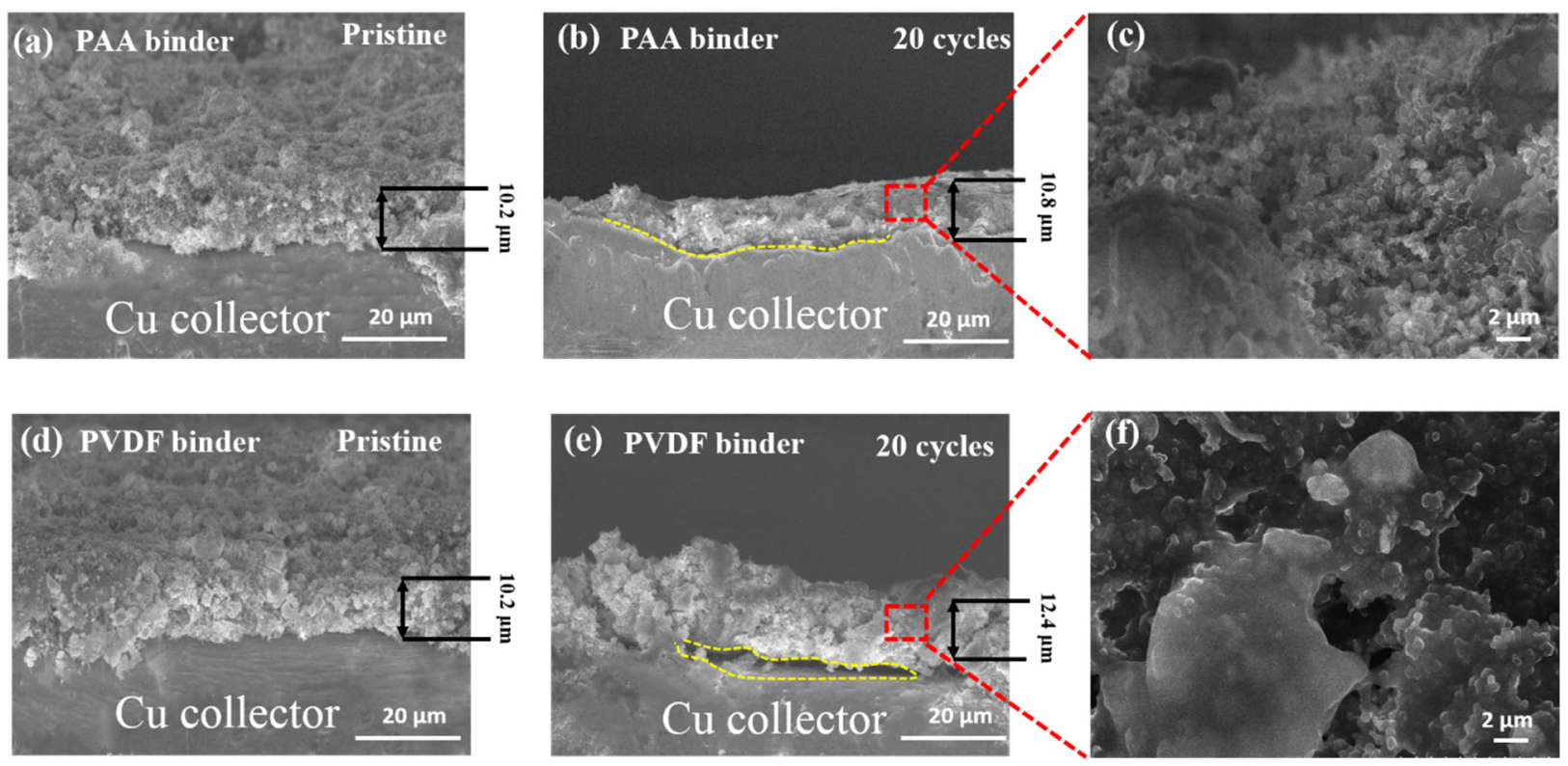

Figure 3. Comparison of the InSb_PAA and InSb_PVDF electrodes before and after 20 cycles. Cross-sectional images of (a) pristine InSb_PAA, (b,c) InSb_PAA after 20 cycles at different magnifications, (d) pristine InSb_PVDF, and $(\mathbf{e}, \mathbf{f})$ InSb_PVDF after 20 cycles at different magnifications. The dashed yellow lines in $(\mathbf{b}, \mathbf{e})$ indicate the boundary between electrode and $\mathrm{Cu}$ collector.

Ex-situ XRD was used to investigate the electrochemical reaction mechanism during the initial lithiation/delithiation process of the InSb electrode (Figure 4a). At a discharge voltage of $0.38 \mathrm{~V}(\mathrm{D}-0.38 \mathrm{~V})$, peaks corresponding to $\mathrm{Li}_{2} \mathrm{Sb}$ and In emerged. When fully discharged $(\mathrm{D}-5 \mathrm{mV}), \mathrm{Li}_{2} \mathrm{In}$ peaks appeared, while $\mathrm{Li}_{2} \mathrm{Sb}$ and In peaks remained. Upon charging to $0.7 \mathrm{~V}(\mathrm{C}-0.7 \mathrm{~V})$, the $\mathrm{Li}_{2} \mathrm{In}$ phase disappeared. At the charging states of 0.98 and $1.12 \mathrm{~V}$ the $\mathrm{Li}_{2} \mathrm{Sb}$ phase vanished. When fully charged to $2.5 \mathrm{~V}(\mathrm{C}-2.5 \mathrm{~V})$, only the peaks matching with InSb re-emerged. The structural transformation of InSb during lithiation/delithiation is summarized as follows:

Discharging:

$$
\mathrm{InSb} \rightarrow \mathrm{Li}_{2} \mathrm{Sb}+\mathrm{In} \rightarrow \mathrm{Li}_{2} \mathrm{Sb}+\mathrm{Li}_{2} \mathrm{In}+\mathrm{In} \text { (partly) }
$$

Charging:

$$
\mathrm{Li}_{2} \mathrm{Sb}+\mathrm{Li}_{2} \mathrm{In}+\mathrm{In} \text { (partly) } \rightarrow \mathrm{In}+\mathrm{Li}_{2} \mathrm{Sb} \rightarrow \mathrm{InSb}
$$

Notably, the InSb phase (major peaks at $39.9^{\circ}$ and $46.5^{\circ}$ ) fully recovered without any impurity peaks after the first cycle, indicating a highly reversible reaction of InSb with $\mathrm{Li}$ ions. This likely correlates with the robust binding between InSb and PAA, which effectively protects the active material from pulverization and delamination caused by volume changes. The ex-situ XRD results demonstrate the conversion and alloying/dealloying mechanism of the InSb electrode during discharge/charge, as schematically illustrated in Figure 4b. 
(a)
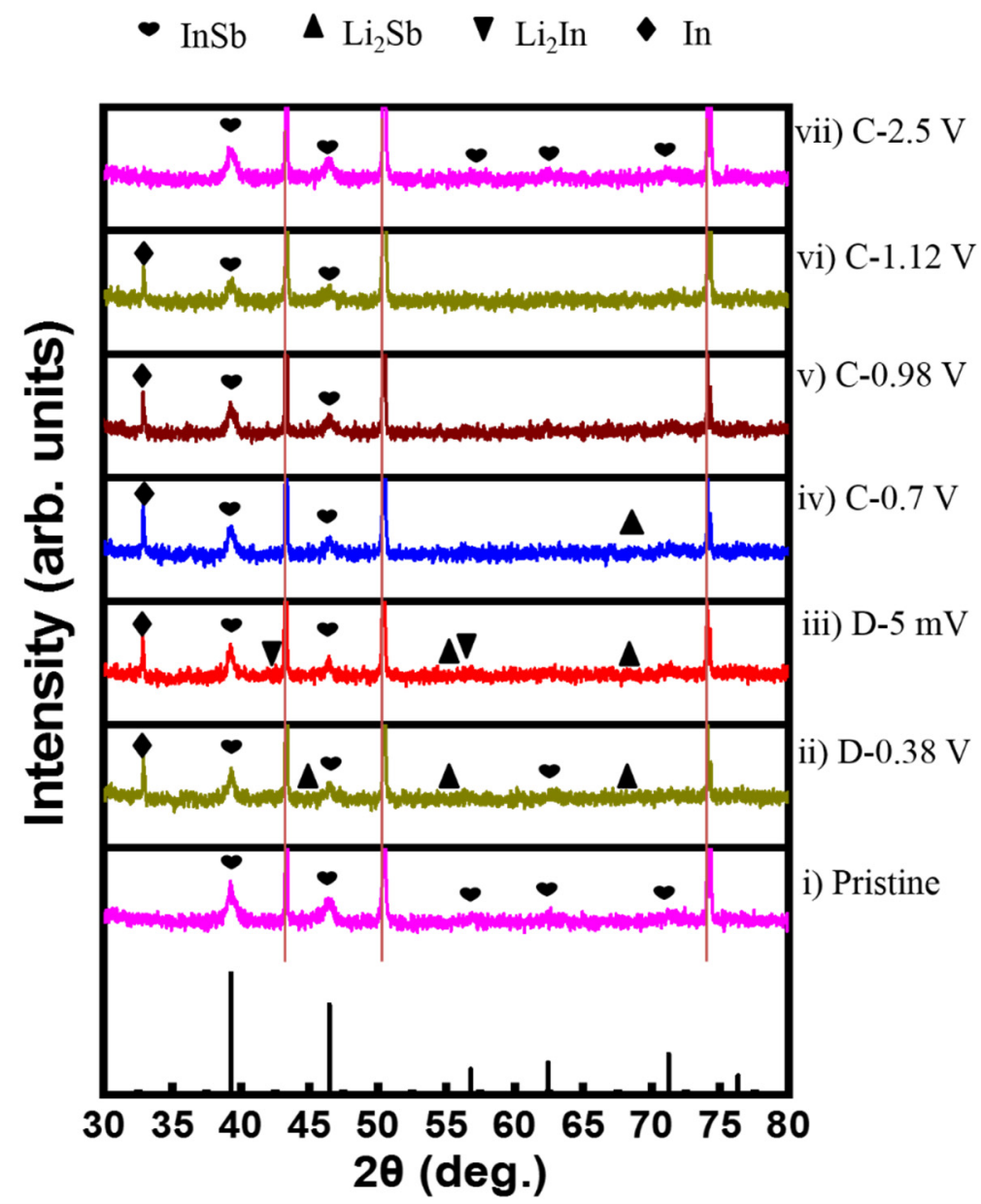

(b)

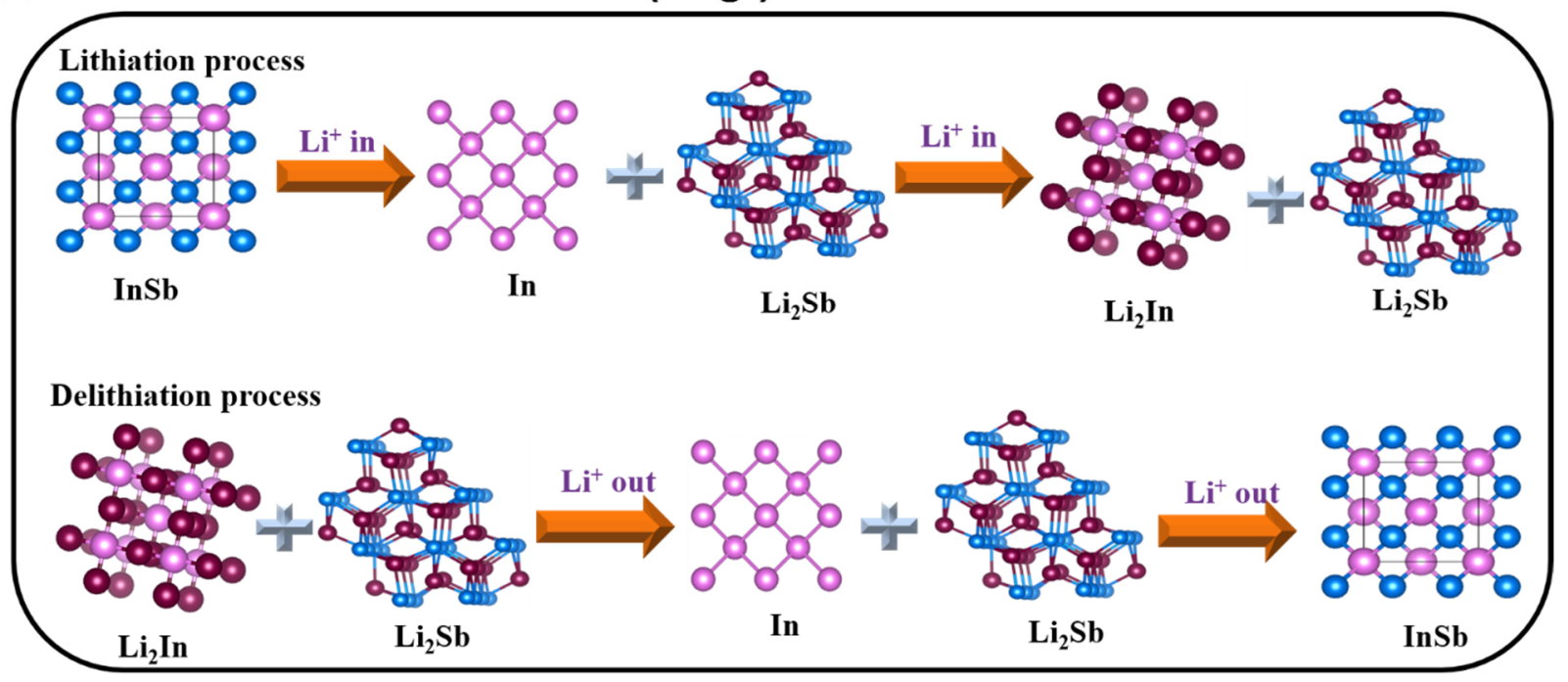

Figure 4. (a) XRD patterns collected at selected potential states in the initial lithiation/delithiation process. (b) Schematic of the electrochemical reaction mechanism of the InSb_PAA electrode during cycling.

Despite the better performance of InSb_PAA compared to that of InSb_PVDF, the InSb_PAA electrode still had a gradual decrease in capacity after $\sim 80$ cycles when measured at $100 \mathrm{~mA} \cdot \mathrm{g}^{-1}$ (Figure 2b). This behavior is also reflected in the coulombic efficiency (CE) variation (Table S2), where the $\mathrm{CE}$ steadily increased until $\sim 60$ cycles, then decreased afterwards. This might be associated with increasing side reactions between InSb_PAA and the electrolyte as the electrode was cycled. These side reactions can be further explained by a differential capacity plot (DCP) analysis of the initial 140 cycles (Figure S5). From this 
analysis, the main reduction (at $\sim 0.86$ and $\sim 0.92 \mathrm{~V}$ ) and oxidation (at $\sim 0.59$ and $0.81 \mathrm{~V}$ ) peaks remained unchanged for 80 cycles, but then became broader and shifted after 80 cycles. This polarization leads to inefficient lithiation/delithiation and a progressive capacity drop after 80 cycles. A similar trend was observed at a high current density (Figure 2c). In this case, the capacity gradually increased until 80 cycles, followed by a slight decrease in subsequent cycles. This trend was also observed in the CE variation (Table S3) and DCP analysis (Figures S6 and S7), where the intensities of the oxidation (at $\sim 0.59$ and $0.81 \mathrm{~V}$ ) and reduction (at $\sim 0.86$ and $\sim 0.92 \mathrm{~V}$ ) peaks generally increased for 60 cycles with a negligible polarization (Figure S6), then decreased in intensity after 60 cycles with a slight polarization (Figure S7). Therefore, the electrochemical performance of InSb_PAA at current densities of 100 and $500 \mathrm{~mA} \cdot \mathrm{g}^{-1}$ was not fully satisfactory, based on these results.

High-performance LIB anode materials frequently use $C$ decoration to overcome the disadvantages of the active materials. Amorphous $C$ provides improved electrical conductivity and acts as a buffer for withstanding the volume change of Li-active materials [53-56]. Therefore, InSb-C (or InSb-C_PAA) was prepared by two sequential steps of HEMM (adding acetylene black to the InSb electrode in the secondary HEMM). The XRD peaks of the as-prepared InSb-C matched well with those of InSb (Figure 5a). The size and shape of the InSb-C were almost unchanged compared to those of InSb (Figure 5b). The presence of InSb nanocrystallites was confirmed with HRTEM, with interplanar distances of $0.374 \mathrm{~nm}$ and $0.229 \mathrm{~nm}((111)$ and (220) phases of InSb, respectively (Figure 5c)), which was consistent with the XRD analysis. The elemental mapping images ( $\mathrm{Sb}$, In, and $\mathrm{C}$ ) revealed evenly distributed constituent elements (Figure $5 \mathrm{~d}$ ). In addition, the uniform distribution of $\mathrm{O}$ confirmed the oxidation of the functional groups on the $\mathrm{InSb}-\mathrm{C}$, as in the case of $\mathrm{InSb}$.

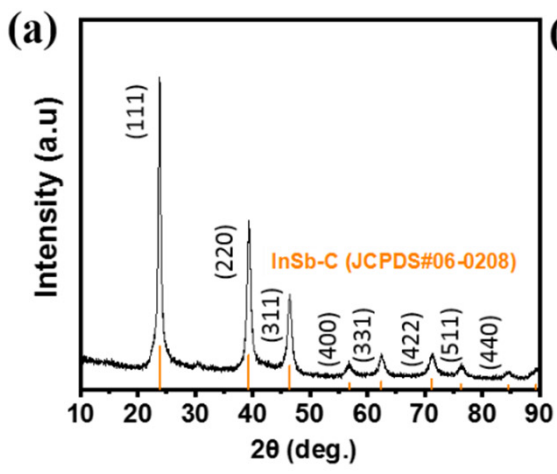

(b)

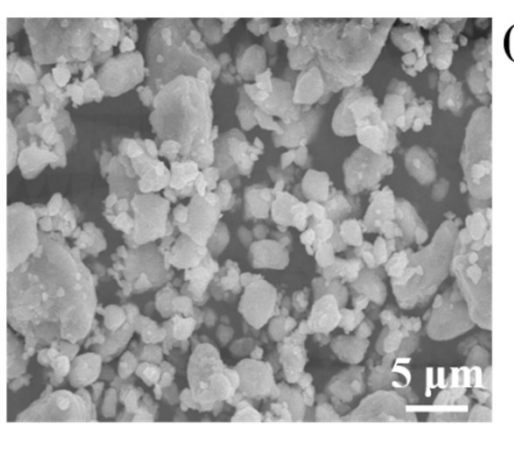

(c)

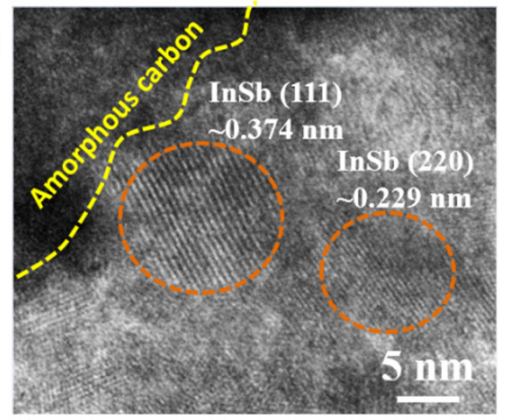

(d)
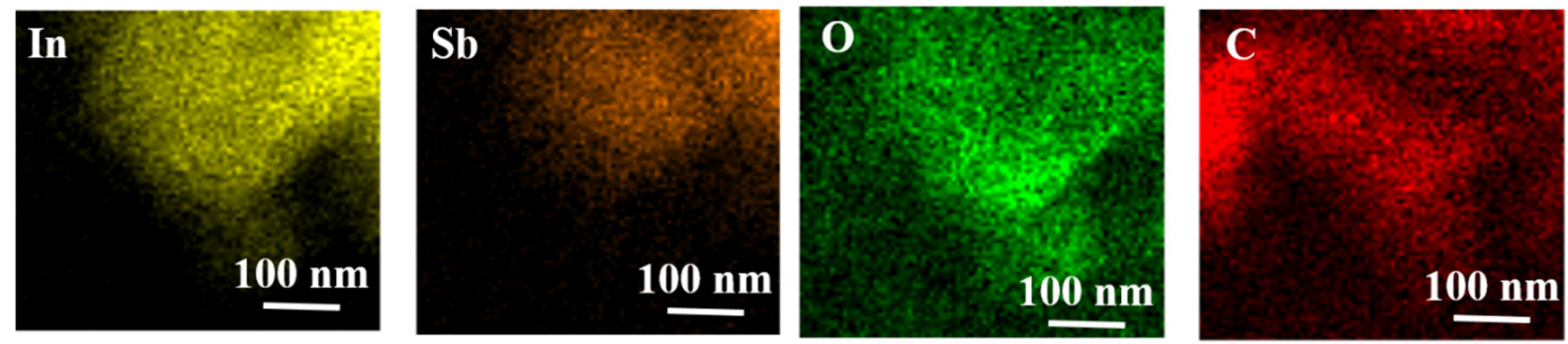

Figure 5. (a) XRD pattern, (b) SEM image, (c) HRTEM image, and (d) EDX elemental maps of In, Sb, O, and C of InSb-C.

The electrochemical performance of the InSb-C_PAA electrode is shown in Figure 6. The initial charge/discharge capacity of InSb-C_PAA was $669 / 540 \mathrm{mAh} \cdot \mathrm{g}^{-1}$ with an ICE of $80.7 \%$ (Figure 6a). From the EDX analysis (Figure S8) and the calculated theoretical capacity of the individual components (Table S4), the capacity contribution from $\mathrm{C}$ in the InSb electrode was estimated to be $\sim 10 \%$. Therefore, the capacity of the electrode was mainly from the active InSb (90\% of the total capacity) while C mainly functioned as a buffer matrix (10\% capacity contribution) that mitigated the volume expansion of the electrode. Remarkably, the measured capacities of InSb_PAA and InSb-C_PAA were 
higher than their theoretical capacities (454 and $435.6 \mathrm{mAh} \cdot \mathrm{g}^{-1}$, respectively, as calculated in Table S5). This additional capacity is most likely due to electrolyte decomposition and interfacial Li-ion storage. Although the specific capacity of InSb-C_PAA was lower than that of InSb_PAA in the initial cycle, the long-term performance of InSb-C_PAA was superior to that of InSb_PAA. In particular, InSb-C_PAA delivered 878 and $634 \mathrm{mAh} \cdot \mathrm{g}^{-1}$ at $100 \mathrm{~mA} \cdot \mathrm{g}^{-1}$ (Figure $6 \mathrm{~b}$ ) and $500 \mathrm{mAg}^{-1}$ (Figure $6 \mathrm{c}$ ) after 150 and 300 cycles, respectively. Notably, a steady capacity increase was observed for InSb-C_PAA during the repeated discharge/charge processes, which was attributed to the creation of a polymer-gelled film from electrolyte decomposition and interfacial Li-ion storage [57-59]. Furthermore, the variations in the DCP profiles as a function of cycle number were studied at current densities of 100 and $500 \mathrm{~mA} \cdot \mathrm{g}^{-1}$ to better understand the steady rise in capacity (Figure S9). In the DCP curves of the InSb-C_PAA electrodes, the overall intensity of the redox potentials increased with increasing cycle number. There was also a minor positive shift in the reduction peaks (at 0.86 and $0.92 \mathrm{~V}$ ) and a slight negative shift in the oxidation peaks (at 0.59 and $0.81 \mathrm{~V}$ ) in the capacity-increasing region. The degree of polarization in InSb-C_PAA was much lower than that of InSb-PAA (Figure S9). Figure S10 compares the CE variation in InSb-C_PAA and InSb_PAA at current densities of 100 and $500 \mathrm{~mA} \cdot \mathrm{g}^{-1}$. The detailed CE values are summarized in Table S6 (at $100 \mathrm{~mA} \cdot \mathrm{g}^{-1}$ ) and Table S7 (at $500 \mathrm{~mA} \cdot \mathrm{g}^{-1}$ ) for the InSb_PAA, InSb_PVDF, and InSb-C_PAA electrodes during the first 10 cycles. As seen in Table S6, InSb-C_PAA had a slightly lower ICE $(80.58 \%)$ than the InSb_PAA (ICE $=81.42 \%$ ) and InSb_PVDF electrodes (ICE = 83.53\%). However, the CE of the InSb-C_PAA electrode significantly increased after the first cycle, exhibiting the highest $\mathrm{CE}$ among the three different electrodes. This trend was also observed at high current densities (Table S7). The high $\mathrm{CE}$ of the InSb-C_PAA electrode after the first cycle indicated a high reversibility of lithiation/delithiation. Figure $6 \mathrm{~d}$ shows the first five CV curves of InSb-C_PAA. In contrast to InSb_PAA and InSb_PVDF, the CV curves of InSb-C_PAA nearly overlapped after the second cycle, exhibiting exceptional cycling stability. The redox peak positions were exactly identical to those observed for InSb_PAA (Figure 2d), indicating that InSb is the main active material. The rate performance (Figure 6e) and normalized capacity retention (Figure 6f) of InSb-C_PAA were measured at various current densities. The average discharge capacities of InSb-C_PAA were 669, 660, 659, 645, 644, and $635 \mathrm{mAh} \cdot \mathrm{g}^{-1}$ at current densities of 0.1 , $0.5,1.0,3.0,5.0$, and $10.0 \mathrm{~A} \cdot \mathrm{g}^{-1}$, respectively (Figure $6 \mathrm{e}$ ), which were significantly greater than those of InSb_PAA and InSb_PVDF. Remarkably, even at a high current density of $10 \mathrm{~A} \cdot \mathrm{g}^{-1}$, the capacity retention of $\mathrm{InSb}-\mathrm{C} \_$PAA was as high as $98 \%$ of its initial capacity (Figure 6f). Even at the current densities higher than $10 \mathrm{~A} \cdot \mathrm{g}^{-1}, \mathrm{InSb}-\mathrm{C} \_$PAA still presented outstanding electrochemical performance with average specific capacities were 627 and $541 \mathrm{mAh} \cdot \mathrm{g}^{-1}$ at 15 and $20 \mathrm{~A} \cdot \mathrm{g}^{-1}$, respectively (Figure S11). In addition, a high-capacity retention $(94.4 \%)$ was achieved when the discharge rate was returned to $0.1 \mathrm{~A} \cdot \mathrm{g}^{-1}$ from $10 \mathrm{~A} \cdot \mathrm{g}^{-1}$, demonstrating the good rate performance of $\mathrm{InSb}-\mathrm{C}_{-}$PAA.

EIS profiles of the InSb_PAA, InSb_PVDF, and InSb-C_PAA electrodes were obtained at the 1 st, 5 th, and 20th cycles (Figure 7$)$. The electrolyte resistance $\left(R_{b}\right)$, SEI layer resistance $\left(R_{\mathrm{SEI}}\right)$, charge-transfer resistance $\left(\mathrm{R}_{\mathrm{ct}}\right)$, interfacial double layer capacitance $\left(\mathrm{C}_{\mathrm{dl}}\right)$, constant phase element $\left(C_{P E}\right)$, and Warburg impedance $\left(Z_{W}\right)$ are all included in the simplified equivalent circuit depicted in Figure 7a. The compressed semi-circles in the mid-frequency region of the Nyquist plots correspond to $R_{c t}$ at the electrode-electrolyte interface. The cells containing the electrode with the PAA binder (InSb_PAA and InSb-C_PAA) showed decreasing semicircles in the low-frequency region with an increase in the cycle number (from 1 to 20 cycles), indicating a gradual decrease in $R_{c t}$ and steady stabilization of the electrode (Figure 7b,d). The $\mathrm{R}_{\mathrm{ct}}$ values of InSb_PAA and InSb-C_PAA (Figure 7b,d) were significantly lower than that of InSb_PVDF (Figure 7c). After 20 cycles, InSb-C_PAA exhibited the lowest $R_{c t}$ value among the electrodes (Table S8). These results help to explain the gradual increase in capacity and performance of the InSb-C_PAA electrode during long-term cycling. 
(a)

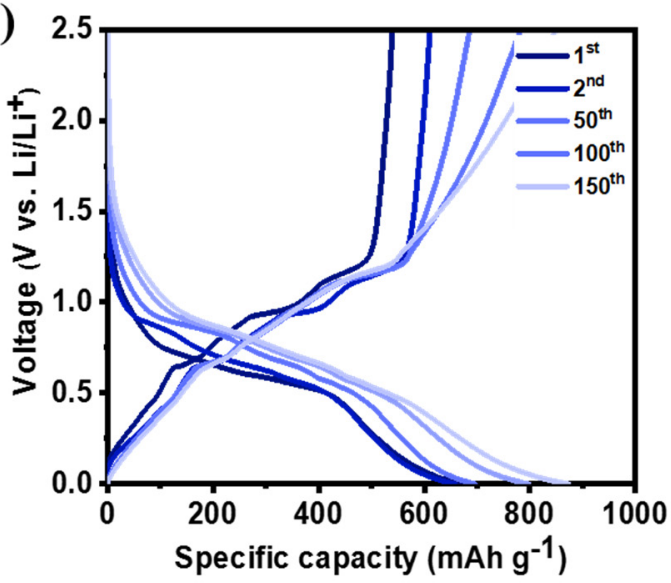

(c)

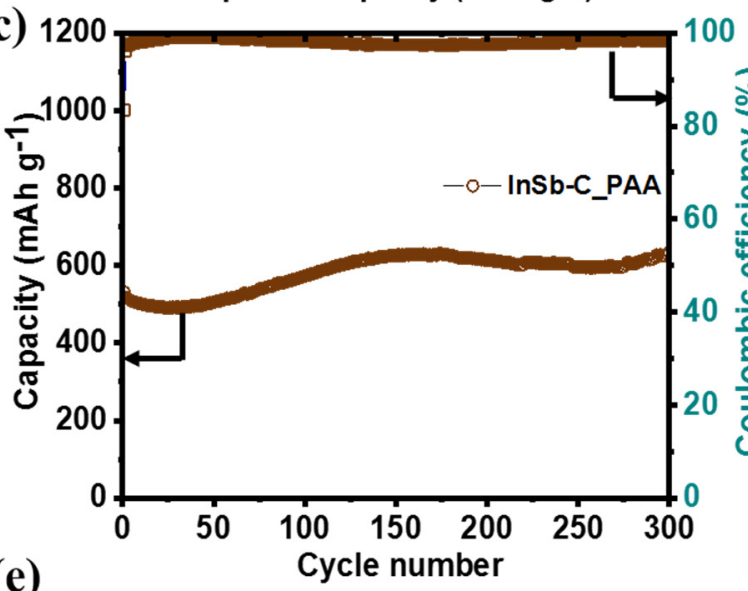

(e)

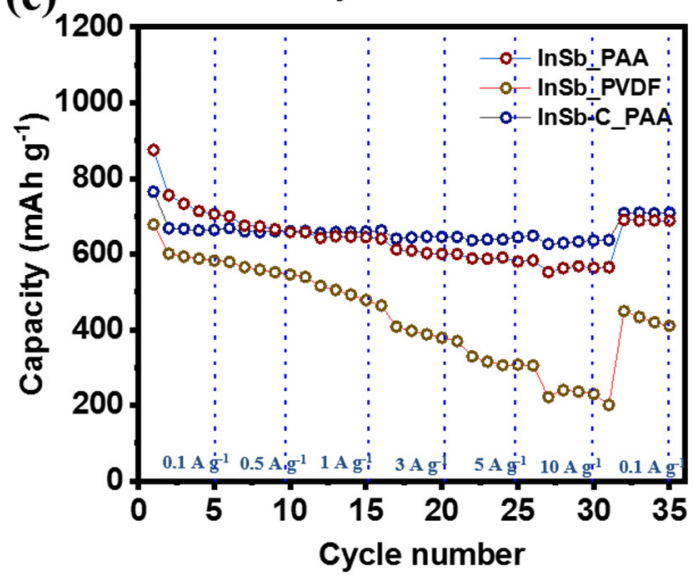

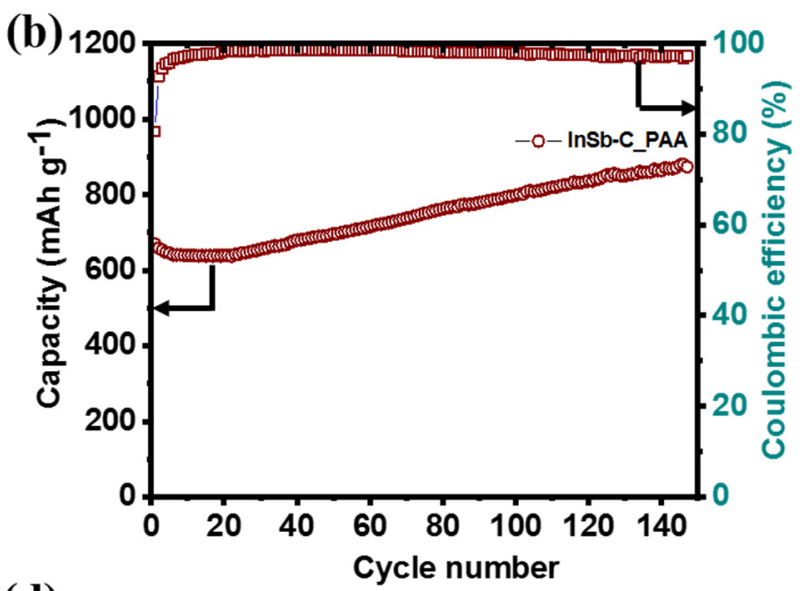

(d)

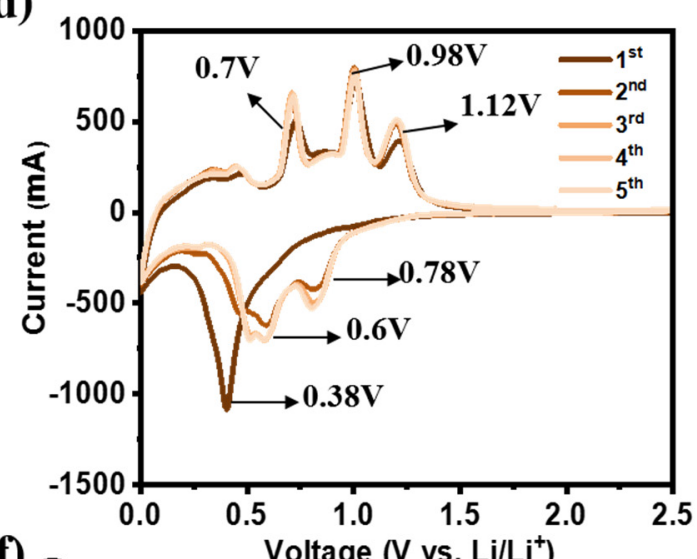

(f)

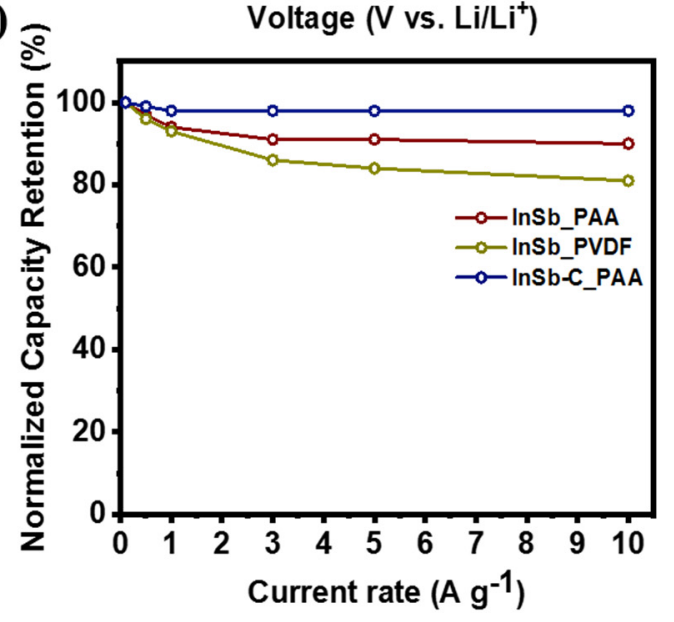

Figure 6. Electrochemical performance of the half-cells. (a) GCD profiles of InSb-C_PAA at a current density of $100 \mathrm{~mA} \cdot \mathrm{g}^{-1}$, cyclic performance of InSb-C_PAA at (b) $100 \mathrm{~mA} \cdot \mathrm{g}^{-1}$ and (c) $500 \mathrm{~mA} \cdot \mathrm{g}^{-1}$, (d) CV curves of InSb-C_PAA, (e) rate capabilities of the composites, and (f) capacity retention of the composites at different current densities. 
(a)

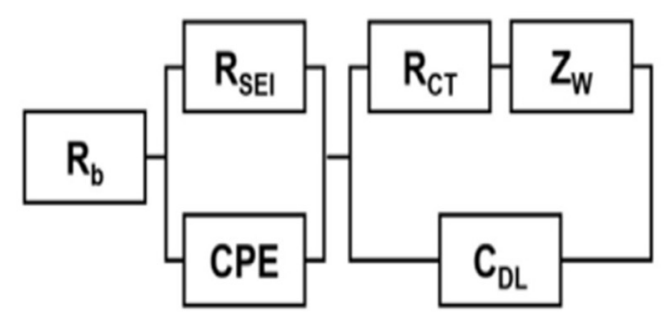

(c)

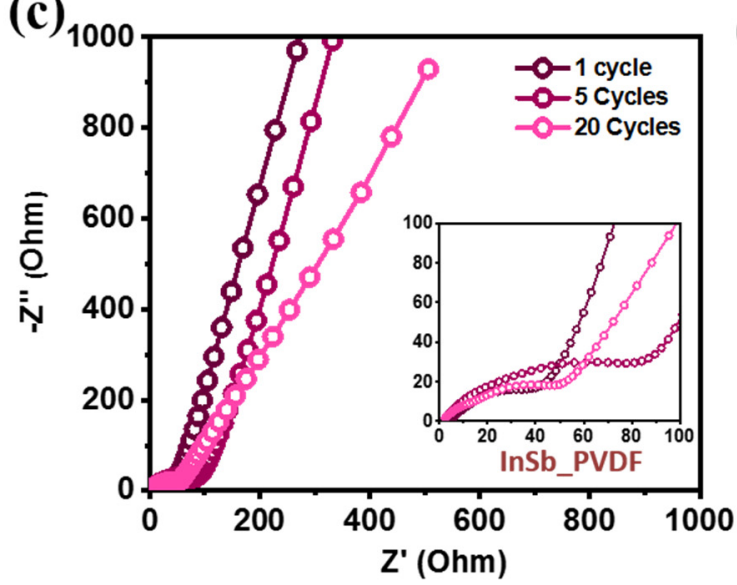

(b)

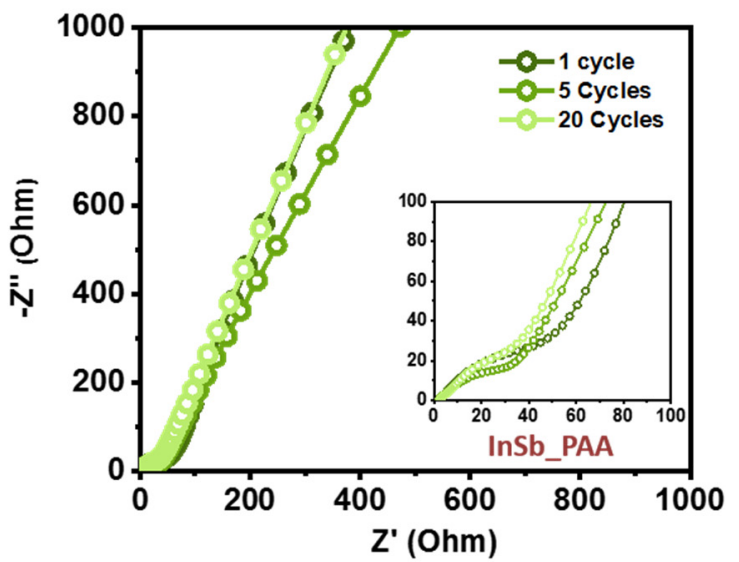

(d)

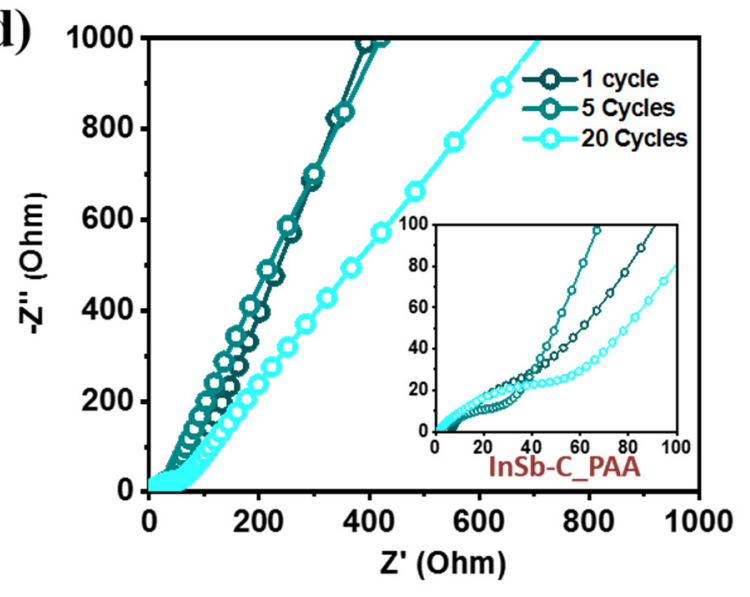

Figure 7. (a) The equivalent circuit. Nyquist plots after 1, 5, and 20 cycles for (b) InSb_PAA, (c) InSb_PVDF, and (d) InSb-C_PAA.

Considering all the results, the Li-ion storage mechanism of the InSb-C_PAA electrode is schematically presented in Figure 8. The overall electrochemical reaction is written as $\mathrm{InSb}+4 \mathrm{Li}^{+}+4 \mathrm{e}^{-} \rightleftarrows \mathrm{Li}_{2} \mathrm{Sb}+\mathrm{Li}_{2} \mathrm{In}$, neglecting the small capacity contribution from the $\mathrm{C}$ matrix. As the discharge proceeds, $\mathrm{Li}_{2} \mathrm{Sb}$ and $\mathrm{Li}_{2} \mathrm{In}$ are formed as products after the reaction with $\mathrm{Li}$ ions. During this reaction, a large volume expansion $\left(\mathrm{Li}_{2} \mathrm{Sb}(\sim 135 \%)\right.$ and $\mathrm{Li}_{2} \mathrm{In}$ $(\sim 297 \%)$ ) causes mechanical stress on the active InSb. Under prolonged cycles, accumulated stress can result in particle agglomeration, pulverization, and delamination. These issues were effectively resolved by employing a PAA binder and a C buffering matrix. PAA is a binder with numerous $\mathrm{COOH}$ functional groups that can form hydrogen bonds with $\mathrm{OH}$ groups on the surfaces of active materials (as determined using FTIR (Figure S1) and XPS analyses (Figure 1e)), thereby stabilizing the electrode structure. The presence of amorphous $\mathrm{C}$ around InSb facilitates charge transport and provides a mechanical buffer for the active InSb. Therefore, the synergistic effect between the PAA binder and amorphous $\mathrm{C}$ contributes to a significant improvement in the electrochemical performance of InSb. Consequently, the performance of the InSb-C_PAA electrode is better than that of most previously reported $\mathrm{Sb}$-based electrodes (Table 1 ). 


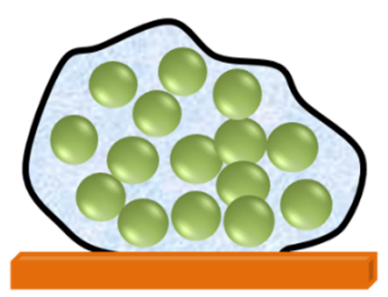

Copper foil InSb

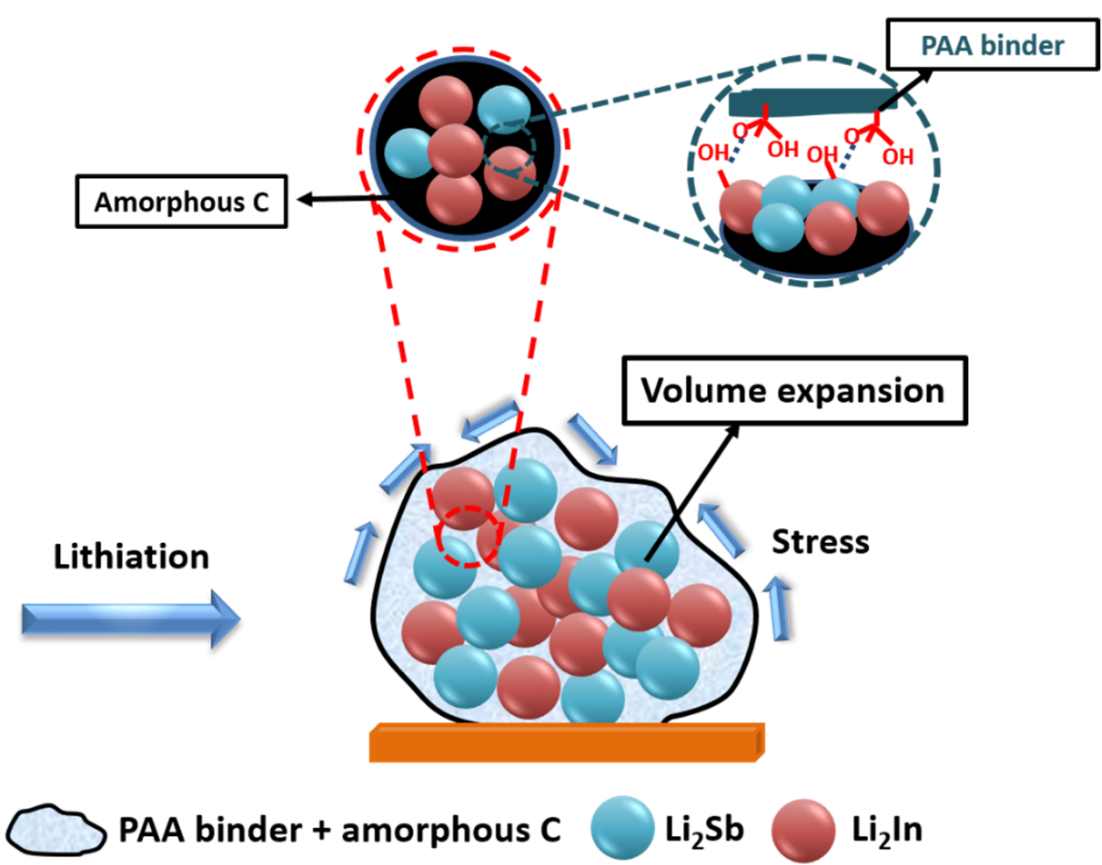

Figure 8. Illustration of the InSb-C_PAA reaction mechanism.

Table 1. Performance comparison of intermetallic Sb-based anodes for LIBs.

\begin{tabular}{|c|c|c|c|c|}
\hline Anode & Cycling Performance & Rate Capability & Synthesis Method & Ref. \\
\hline $\mathrm{Cu}_{2} \mathrm{Sb}$ & $290 \mathrm{mAh} \cdot \mathrm{g}^{-1}$ after 25 cycles & - & Ball milling & [60] \\
\hline $\mathrm{Mo}_{3} \mathrm{Sb}_{7}$ & $\begin{array}{c}350 \mathrm{mAh} \cdot \mathrm{g}^{-1} \text { after } 100 \text { cycles at } \\
0.12 \mathrm{C}\end{array}$ & $300 \mathrm{mAh} \cdot \mathrm{g}^{-1}$ at $100 \mathrm{C}$ & Furnace & [61] \\
\hline $\mathrm{CoSb}$ & $\begin{array}{c}448 \mathrm{mAh} \cdot \mathrm{g}^{-1} \text { after } 1000 \text { cycles at } \\
0.66 \mathrm{~A} \cdot \mathrm{g}^{-1}\end{array}$ & - & Facile colloidal synthesis & [62] \\
\hline NiSb@C & $\begin{array}{c}405 \mathrm{mAh} \cdot \mathrm{g}^{-1} \text { after } 1000 \text { cycles at } \\
0.1 \mathrm{~A} \mathrm{~g}^{-1}\end{array}$ & $393 \mathrm{mAh} \cdot \mathrm{g}^{-1}$ at $2.0 \mathrm{~A} \cdot \mathrm{g}^{-1}$ & Freezing drying & [63] \\
\hline NiSb hollow nanosphere & $\begin{array}{c}420 \mathrm{mAh} \cdot \mathrm{g}^{-1} \text { after } 50 \text { cycles at } \\
0.1 \mathrm{~A} \cdot \mathrm{g}^{-1}\end{array}$ & $352 \mathrm{mAh} \cdot \mathrm{g}^{-1}$ at $0.8 \mathrm{~A} \cdot \mathrm{g}^{-1}$ & Galvanic replacement reaction & [64] \\
\hline $\mathrm{NiSb} / \mathrm{C}$ nanosheet & $\begin{array}{c}393 \mathrm{mAh} \cdot \mathrm{g}^{-1} \text { after } 1000 \text { cycles at } \\
2 \mathrm{C}\end{array}$ & $325 \mathrm{mAh} \cdot \mathrm{g}^{-1}$ at $10 \mathrm{C}$ & $\begin{array}{c}\text { Hydrothermal } \\
\text { low-temperature carbothermic } \\
\text { reduction }\end{array}$ & [65] \\
\hline SnSb@Carbon fiber & $\begin{array}{c}674 \mathrm{mAh} \cdot \mathrm{g}^{-1} \text { after } 100 \text { cycles at } \\
0.1 \mathrm{~A} \cdot \mathrm{g}^{-1}\end{array}$ & $163 \mathrm{mAh} \cdot \mathrm{g}^{-1}$ at $1.6 \mathrm{~A} \cdot \mathrm{g}^{-1}$ & Electrospinning & [66] \\
\hline $\mathrm{ZnSb} / \mathrm{C}$ & $\begin{array}{c}481 \mathrm{mAh} \cdot \mathrm{g}^{-1} \text { after } 240 \text { cycles at } \\
0.1 \mathrm{~A} \cdot \mathrm{g}^{-1}\end{array}$ & $426 \mathrm{mAh} \cdot \mathrm{g}^{-1}$ at $0.5 \mathrm{~A} \cdot \mathrm{g}^{-1}$ & Annealing & [67] \\
\hline $\mathrm{TiSb}_{2}$ & $420 \mathrm{mAh} \cdot \mathrm{g}^{-1}$ after 120 cycles at $1 \mathrm{C}$ & $300 \mathrm{mAh} \cdot \mathrm{g}^{-1}$ at $12 \mathrm{C}$ & Furnace & [68] \\
\hline $\begin{array}{l}\text { InSb_PAA } \\
\text { InSb-C_PAA }\end{array}$ & $\begin{array}{c}640 \mathrm{mAh} \cdot \mathrm{g}^{-1} \text { after } 140 \text { cycles } \\
846 \mathrm{mAh} \cdot \mathrm{g}^{-1} \text { after } 150 \text { cycles at } \\
0.1 \mathrm{~A} \cdot \mathrm{g}^{-1}\end{array}$ & $\begin{array}{l}594 \mathrm{mAh} \cdot \mathrm{g}^{-1} \text { at } 10 \mathrm{~A} \cdot \mathrm{g}^{-1} \\
716 \mathrm{mAh} \cdot \mathrm{g}^{-1} \text { at } 10 \mathrm{~A} \cdot \mathrm{g}^{-1}\end{array}$ & Ball milling & This work \\
\hline
\end{tabular}

\section{Conclusions}

In summary, InSb and InSb-C were successfully synthesized via HEMM and studied as potential anodes for LIBs. The crystal structure, morphology, and chemical state of these materials were characterized using XRD, SEM, HRTEM, EDX, and XPS. Electrochemical measurements revealed that the PAA binder played a significant role in improving the performance of the InSb-based electrode over conventional PVDF owing to the formation of hydrogen bonds with InSb, which contributed to the strong adhesion between the active materials and current collectors. The addition of amorphous $C$ to InSb improved the mechanical stability and electrical conductivity. As a result, InSb-C_PAA electrodes delivered a high reversible specific capacity $\left(878 \mathrm{mAh} \cdot \mathrm{g}^{-1}\right.$ at $100 \mathrm{~mA} \cdot \mathrm{g}^{-1}$ after 140 cycles $)$ and good rate capability (capacity retention of $98 \%$ at $10 \mathrm{~A} \cdot \mathrm{g}^{-1}$ as compared to $0.1 \mathrm{~A} \cdot \mathrm{g}^{-1}$ ), which outperforms most of the Sb-based electrodes recently reported. The synergistic 
effect of the PAA binder and amorphous $\mathrm{C}$ is responsible for the improved electrochemical performance of InSb-C_PAA. Therefore, InSb-C_PAA can be considered as a potential anode material for next-generation LIBs.

Supplementary Materials: The following are available online at https://www.mdpi.com/article/ 10.3390/nano11123420/s1, Figure S1: FT-IR results of InSb powder; Figure S2: GCD curves of InSb_PVDF; Figure S3: SEM images of (a and b) InSb_PAA, (c and d) InSb_PVDF binder at different magnification; Figure S4: CV curves of InSb_PVDF from first to fifth cycle; Figure S5: DCP of InSb_PAA during 140 cycles measured at $100 \mathrm{~mA} \cdot \mathrm{g}^{-1}$ : (a) 1-60 cycle, (b) 80-140 cycle. Enlarged view of (c) reduction peak and (d) oxidation peak; Figure S6: (a) DCP of InSb_PAA during initial 60 cycles measured at $500 \mathrm{~mA} \cdot \mathrm{g}^{-1}$. Enlarged view of (b) oxidation peak and (c) reduction peak; Figure S7: (a) DCP of InSb_PAA from 60 th to 100 th cycle measured at $500 \mathrm{~mA} \cdot \mathrm{g}^{-1}$. Enlarged view of (b) oxidation peak and (c) reduction peak; Figure S8: EDX spectrum of synthesized InSb-C; Figure S9: DCP profiles of InSb-C_PAA electrodes at current density of (a) $100 \mathrm{~mA} \cdot \mathrm{g}^{-1}$ during 140 cycles and (b) $500 \mathrm{~mA} \cdot \mathrm{g}^{-1}$ during 300 cycles; Figure S10: Coulombic efficieny of InSb_PAA, InSb_PVDF, and InSb-C_PAA at current density of (a) 100 and (b) $500 \mathrm{~mA} \cdot \mathrm{g}^{-1}$; Figure S11: Cyclic performance of InSb-C_PAA at $15 \mathrm{~A} \cdot \mathrm{g}^{-1}$ and $20 \mathrm{~A} \cdot \mathrm{g}^{-1}$; Table S1: Crystallite size of InSb calculated using Scherrer equation; Table S2: Coulombic efficiency variation of InSb_PAA at various cycle numbers measured at $100 \mathrm{~mA} \cdot \mathrm{g}^{-1}$; Table S3: Coulombic efficiency variation of InSb_PAA at various cycle numbers measured at $500 \mathrm{~mA} \cdot \mathrm{g}^{-1}$; Table S4: Calculation of capacity contribution of InSb and C in the InSb-C composite; Table S5: Calculation of theoretical capacity of InSb and InSb-C; Table S6: Coulombic efficiency of InSb_PAA, InSb_PVDF, and InSb-C_PAA at current density of $100 \mathrm{~mA} \cdot \mathrm{g}^{-1}$ for initial 10 cycles; Table S7: Coulombic efficiency of InSb_PAA, InSb_PVDF, and InSb-C_PAA at current density of $500 \mathrm{~mA} \cdot \mathrm{g}^{-1}$ for initial 10 cycles; Table S8: The charge-transfer resistance $\left(\mathrm{R}_{\mathrm{ct}}\right)$ of InSb_PAA, InSb_PVDF, InSb-C_PAA.

Author Contributions: Conceptualization, J.H. and I.T.K.; validation, V.P.H.H.; investigation, V.P.H.H.; writing—original draft preparation, V.P.H.H.; writing—review and editing, J.H. and I.T.K.; supervision, J.H. and I.T.K.; funding acquisition, J.H. All authors have read and agreed to the published version of the manuscript.

Funding: This work was supported by the Basic Science Research Capacity Enhancement Project through Korea Basic Science Institute (National Research Facilities and Equipment Center) grant funded by the Ministry of Education (2019R1A6C1010016) and the Korea Institute of Energy Technology Evaluation and Planning (KETEP) and the Ministry of Trade, Industry \& Energy (MOTIE) of the Republic of Korea (No. 20194030202290).

Institutional Review Board Statement: Not applicable.

Informed Consent Statement: Not applicable.

Data Availability Statement: Not applicable.

Conflicts of Interest: The authors declare no competing interest.

\section{References}

1. Chen, T.; Jin, Y.; Lv, H.; Yang, A.; Liu, M.; Chen, B.; Xie, Y.; Chen, Q. Applications of lithium-ion batteries in grid-scale energy storage systems. Trans. Tianjin Univ. 2020, 26, 208-217. [CrossRef]

2. Armand, M.; Tarascon, J.-M. Building better batteries. Nature 2008, 451, 652-657. [CrossRef]

3. $\mathrm{Xu}$, J.; Wang, D.; Kong, S.; Li, R.; Hong, Z.; Huang, F.Q. Pyrochlore phase $\mathrm{Ce}_{2} \mathrm{Sn}_{2} \mathrm{O}_{7}$ via an atom-confining strategy for reversible lithium storage. J. Mater. Chem. A 2020, 8, 5744-5749. [CrossRef]

4. Kim, T.; Song, W.; Son, D.-Y.; Ono, L.K.; Qi, Y. Lithium-ion batteries: Outlook on present, future, and hybridized technologies. J. Mater. Chem. A 2019, 7, 2942-2964. [CrossRef]

5. Meng, J.; Guo, H.; Niu, C.; Zhao, Y.; Xu, L.; Li, Q.; Mai, L. Advances in structure and property optimizations of battery electrode materials. Joule 2017, 1, 522-547. [CrossRef]

6. Goriparti, S.; Miele, E.; De Angelis, F.; Di Fabrizio, E.; Zaccaria, R.P.; Capiglia, C. Review on recent progress of nanostructured anode materials for Li-ion batteries. J. Power Sources 2014, 257, 421-443. [CrossRef]

7. Jiao, X.; Liu, Y.; Li, B.; Zhang, W.; He, C.; Zhang, C.; Yu, Z.; Gao, T.; Song, J. Amorphous phosphorus-carbon nanotube hybrid anode with ultralong cycle life and high-rate capability for lithium-ion batteries. Carbon 2019, 148, 518-524. [CrossRef] 
8. Mun, Y.S.; Pham, T.N.; Bui, V.K.H.; Tanaji, S.T.; Lee, H.U.; Lee, G.-W.; Choi, J.S.; Kim, I.T.; Lee, Y.-C. Tin oxide evolution by heat-treatment with tin-aminoclay (SnAC) under argon condition for lithium-ion battery (LIB) anode applications. J. Power Sources 2019, 437, 226946. [CrossRef]

9. Nguyen, T.L.; Park, D.; Kim, I.T. $\mathrm{Fe}_{\mathrm{x}} \mathrm{Sn}_{\mathrm{y}} \mathrm{O}_{\mathrm{z}}$ composites as anode materials for lithium-ion storage. J. Nanosci. Nanotechnol. 2019, 19, 6636-6640. [CrossRef] [PubMed]

10. Nguyen, T.L.; Kim, J.H.; Kim, I.T. Electrochemical performance of $\mathrm{Sn} / \mathrm{SnO} / \mathrm{Ni}_{3} \mathrm{Sn}$ composite anodes for lithium-ion batteries. J. Nanosci. Nanotechnol. 2019, 19, 1001-1005. [CrossRef]

11. Pham, T.N.; Tanaji, S.T.; Choi, J.S.; Lee, H.U.; Kim, I.T.; Lee, Y.C. Preparation of Sn-aminoclay (SnAC)-templated Fe ${ }_{3} \mathrm{O}_{4}$ nanoparticles as an anode material for lithium-ion batteries. RSC Adv. 2019, 9, 10536-10545. [CrossRef]

12. Nguyen, T.; Kim, I. Ag nanoparticle-decorated $\mathrm{MoS}_{2}$ nanosheets for enhancing electrochemical performance in lithium storage. Nanomaterials 2021, 11, 626. [CrossRef] [PubMed]

13. Nguyen, T.P.; Kim, I.T. Self-assembled few-layered $\mathrm{MoS}_{2}$ on $\mathrm{SnO}_{2}$ anode for enhancing lithium-ion storage. Nanomaterials 2020, 10, 2558. [CrossRef]

14. Preman, A.N.; Lee, H.; Yoo, J.; Kim, I.T.; Saito, T.; Ahn, S.-K. Progress of 3D network binders in silicon anodes for lithium ion batteries. J. Mater. Chem. A 2020, 8, 25548-25570. [CrossRef]

15. Nguyen, T.P.; Kim, I.T. $\mathrm{W}_{2} \mathrm{C} / \mathrm{WS}_{2}$ alloy nanoflowers as anode materials for lithium-ion storage. Nanomaterials 2020, 10,1336 . [CrossRef] [PubMed]

16. Kim, W.S.; Vo, T.N.; Kim, I.T. GeTe-TiC-C composite anodes for li-ion storage. Materials 2020, 13, 4222. [CrossRef]

17. Vo, T.N.; Kim, D.S.; Mun, Y.S.; Lee, H.J.; Ahn, S.-K.; Kim, I.T. Fast charging sodium-ion batteries based on Te-P-C composites and insights to low-frequency limits of four common equivalent impedance circuits. Chem. Eng. J. 2020, 398, 125703. [CrossRef]

18. Park, C.-M.; Kim, J.-H.; Kim, H.; Sohn, H.-J. Li-alloy based anode materials for Li secondary batteries. Chem. Soc. Rev. 2010, 39, 3115-3141. [CrossRef]

19. Obrovac, M.N.; Chevrier, V.L. Alloy negative electrodes for li-ion batteries. Chem. Rev. 2014, 114, 11444-11502. [CrossRef]

20. Lai, S.Y.; Knudsen, K.D.; Sejersted, B.T.; Ulvestad, A.; Mæhlen, J.P.; Koposov, A.Y. Silicon nanoparticle ensembles for lithium-ion batteries elucidated by small-angle neutron scattering. ACS Appl. Energy Mater. 2019, 2, 3220-3227. [CrossRef]

21. Sun, Y.; Wang, L.; Li, Y.; Li, Y.; Lee, H.R.; Pei, A.; He, X.; Cui, Y. Design of red phosphorus nanostructured electrode for fast-charging lithium-ion batteries with high energy density. Joule 2019, 3, 1080-1093. [CrossRef]

22. Liu, S.; Feng, J.; Bian, X.; Qian, Y.; Liu, J.; Xu, H. Nanoporous germanium as high-capacity lithium-ion battery anode. Nano Energy 2015, 13, 651-657. [CrossRef]

23. Wang, L.; Wang, Y.; Xia, Y. A high performance lithium-ion sulfur battery based on a $\mathrm{Li}_{2} \mathrm{~S}$ cathode using a dual-phase electrolyte. Energy Environ. Sci. 2015, 8, 1551-1558. [CrossRef]

24. Nam, K.-H.; Park, C.-M. Layered $\mathrm{Sb}_{2} \mathrm{Te}_{3}$ and its nanocomposite: A new and outstanding electrode material for superior rechargeable Li-ion batteries. J. Mater. Chem. A 2016, 4, 8562-8565. [CrossRef]

25. Hou, H.; Jing, M.; Yang, Y.; Zhu, Y.; Fang, L.; Song, W.; Pan, C.; Yang, X.; Ji, X. Sodium/lithium storage behavior of antimony hollow nanospheres for rechargeable batteries. ACS Appl. Mater. Interfaces 2014, 6, 16189-16196. [CrossRef] [PubMed]

26. Luo, W.; Li, F.; Gaumet, J.-J.; Magri, P.; Diliberto, S.; Zhou, L.; Mai, L. Bottom-up confined synthesis of nanorod-in-nanotube structured $\mathrm{Sb}-\mathrm{N}-\mathrm{C}$ for durable lithium and sodium storage. Adv. Energy Mater. 2018, 8, 1703237. [CrossRef]

27. Nam, K.-H.; Park, C.-M. 2D layered $\mathrm{Sb}_{2} \mathrm{Se}_{3}$-based amorphous composite for high-performance Li- and Na-ion battery anodes. J. Power Sources 2019, 433, 126639. [CrossRef]

28. Darwiche, A.; Marino, C.; Sougrati, M.T.; Fraisse, B.; Stievano, L.; Monconduit, L. Better cycling performances of bulk Sb in Na-Ion batteries compared to Li-Ion Systems: An unexpected electrochemical mechanism. J. Am. Chem. Soc. 2012, 134, $20805-20811$. [CrossRef]

29. Yi, Z.; Han, Q.; Geng, D.; Wu, Y.; Cheng, Y.; Wang, L. One-pot chemical route for morphology-controllable fabrication of Sn-Sb micro/nano-structures: Advanced anode materials for lithium and sodium storage. J. Power Sources 2017, 342, 861-871. [CrossRef]

30. Hou, H.; Jing, M.; Yang, Y.; Zhang, Y.; Song, W.; Yang, X.; Chen, J.; Chen, Q.; Ji, X. Antimony nanoparticles anchored on interconnected carbon nanofibers networks as advanced anode material for sodium-ion batteries. J. Power Sources 2015, 284, 227-235. [CrossRef]

31. Liu, Z.; Yu, X.-Y.; Lou, X.W.; Paik, U. Sb-C coaxial nanotubes as a superior long-life and high-rate anode for sodium ion batteries. Energy Environ. Sci. 2016, 9, 2314-2318. [CrossRef]

32. Zhao, X.; Vail, S.A.; Lu, Y.; Song, J.; Pan, W.; Evans, D.R.; Lee, J.-J. Antimony/graphitic carbon composite anode for highperformance sodium-ion batteries. ACS Appl. Mater. Interfaces 2016, 8, 13871-13878. [CrossRef]

33. Yi, Z.; Han, Q.; Zan, P.; Wu, Y.; Cheng, Y.; Wang, L. Sb nanoparticles encapsulated into porous carbon matrixes for highperformance lithium-ion battery anodes. J. Power Sources 2016, 331, 16-21. [CrossRef]

34. Yang, Q.; Zhou, J.; Zhang, G.; Guo, C.; Li, M.; Zhu, Y.; Qian, Y. Sb nanoparticles uniformly dispersed in 1-D N-doped porous carbon as anodes for Li-ion and Na-ion batteries. J. Mater. Chem. A 2017, 5, 12144-12148. [CrossRef]

35. Wan, F.; Guo, J.-Z.; Zhang, X.-H.; Zhang, J.-P.; Sun, H.-Z.; Yan, Q.; Han, D.-X.; Niu, L.; Wu, X.-L. In situ binding Sb nanospheres on graphene via oxygen bonds as superior anode for ultrafast sodium-ion batteries. ACS Appl. Mater. Interfaces 2016, 8, 7790-7799. [CrossRef] [PubMed] 
36. Yang, C.; Li, W.; Yang, Z.; Gu, L.; Yu, Y. Nanoconfined antimony in sulfur and nitrogen co-doped three-dimensionally (3D) interconnected macroporous carbon for high-performance sodium-ion batteries. Nano Energy 2015, 18, 12-19. [CrossRef]

37. Yim, T.; Choi, S.J.; Jo, Y.N.; Kim, T.-H.; Kim, K.J.; Jeong, G.; Kim, Y.-J. Effect of binder properties on electrochemical performance for silicon-graphite anode: Method and application of binder screening. Electrochim. Acta 2014, 136, 112-120. [CrossRef]

38. Choi, S.; Kwon, T.-W.; Coskun, A.; Choi, J.W. Highly elastic binders integrating polyrotaxanes for silicon microparticle anodes in lithium ion batteries. Science 2017, 357, 279-283. [CrossRef] [PubMed]

39. Wu, M.; Xiao, X.; Vukmirovic, N.; Xun, S.; Das, P.K.; Song, X.; Olalde-Velasco, P.; Wang, D.; Weber, A.Z.; Wang, L.-W.; et al. Toward an ideal polymer binder design for high-capacity battery anodes. J. Am. Chem. Soc. 2013, 135, 12048-12056. [CrossRef] [PubMed]

40. Koo, B.; Kim, H.; Cho, Y.; Lee, K.T.; Choi, N.-S.; Cho, J. A highly cross-linked polymeric binder for high-performance silicon negative electrodes in lithium ion batteries. Angew. Chem. Int. Ed. 2012, 51, 8762-8767. [CrossRef]

41. Mazouzi, D.; Karkar, Z.; Hernandez, C.R.; Manero, P.J.; Guyomard, D.; Roué, L.; Lestriez, B. Critical roles of binders and formulation at multiscales of silicon-based composite electrodes. J. Power Sources 2015, 280, 533-549. [CrossRef]

42. Magasinski, A.; Zdyrko, B.; Kovalenko, I.; Hertzberg, B.; Burtovyy, R.; Huebner, C.F.; Fuller, T.F.; Luzinov, I.; Yushin, G. Toward efficient binders for Li-Ion battery Si-Based anodes: Polyacrylic acid. ACS Appl. Mater. Interfaces 2010, 2, 3004-3010. [CrossRef] [PubMed]

43. Key, B.; Bhattacharyya, R.; Morcrette, M.; Seznéc, V.; Tarascon, J.-M.; Grey, C. Real-time NMR investigations of structural changes in silicon electrodes for Lithium-Ion batteries. J. Am. Chem. Soc. 2009, 131, 9239-9249. [CrossRef]

44. Madelung, O.; Rössler, U.; Schulz, M. Indium antimonide (InSb), carrier concentrations: Datasheet from Landolt-BörnsteinGroup III Condensed Matter Volume 41A1ß. In Group IV Elements, IV-IV and III-V Compounds. Part b-Electronic, Transport, Optical and Other Properties; Springer: Berlin, Germany, 2002; pp. 1-6. [CrossRef]

45. Isaacson, R.A. Electron spin resonance in n-Type InSb. Phys. Rev. 1968, 169, 312-314. [CrossRef]

46. Orlov, V.G.; Sergeev, G. Numerical simulation of the transport properties of indium antimonide. Phys. Solid State 2013, 55, 2215-2222. [CrossRef]

47. Agubra, V.; Fergus, J. Lithium ion battery anode aging mechanisms. Materials 2013, 6, 1310-1325. [CrossRef]

48. Joho, F.; Rykart, B.; Blome, A.; Novák, P.; Wilhelm, H.; Spahr, M.E. Relation between surface properties, pore structure and first-cycle charge loss of graphite as negative electrode in lithium-ion batteries. J. Power Sources 2001, 97, 78-82. [CrossRef]

49. Tran, T.D.; Feikert, J.H.; Pekala, R.W.; Kinoshita, K. Rate effect on lithium-ion graphite electrode performance. J. Appl. Electrochem. 1996, 26, 1161-1167. [CrossRef]

50. Bläubaum, L.; Röder, F.; Nowak, C.; Chan, H.S.; Kwade, A.; Krewer, U. Impact of particle size distribution on performance of Lithium-Ion batteries. ChemElectroChem 2020, 7, 4755-4766. [CrossRef]

51. Roselin, L.S.; Juang, R.-S.; Hsieh, C.-T.; Sagadevan, S.; Umar, A.; Selvin, R.; Hegazy, H.H. Recent advances and perspectives of carbon-based nanostructures as anode materials for Li-ion batteries. Materials 2019, 12, 1229. [CrossRef]

52. Röder, F.; Braatz, R.D.; Krewer, U. Multi-scale simulation of heterogeneous surface film growth mechanisms in Lithium-Ion batteries. J. Electrochem. Soc. 2017, 164, E3335-E3344. [CrossRef]

53. Dong, Y.; Yang, S.; Zhang, Z.; Lee, J.-M.; Zapien, J.A. Enhanced electrochemical performance of lithium ion batteries using $\mathrm{Sb}_{2} \mathrm{~S}_{3}$ nanorods wrapped in graphene nanosheets as anode materials. Nanoscale 2018, 10, 3159-3165. [CrossRef]

54. Wang, X.; Hwang, J.-Y.; Myung, S.-T.; Hassoun, J.; Sun, Y.-K. Graphene decorated by indium sulfide nanoparticles as highperformance anode for sodium-ion batteries. ACS Appl. Mater. Interfaces 2017, 9, 23723-23730. [CrossRef] [PubMed]

55. Ganesan, V.; Nam, K.-H.; Park, C.-M. Robust polyhedral CoTe ${ }_{2}-\mathrm{C}$ nanocomposites as high-performance Li- and Na-Ion battery anodes. ACS Appl. Energy Mater. 2020, 3, 4877-4887. [CrossRef]

56. Zhang, W.; Zhang, Q.; Shi, Q.; Xin, S.; Wu, J.; Zhang, C.-L.; Qiu, L.; Zhang, C. Facile synthesis of carbon-coated porous $\mathrm{Sb}_{2} \mathrm{Te}_{3}$ nanoplates with high alkali metal ion storage. ACS Appl. Mater. Interfaces 2019, 11, 29934-29940. [CrossRef] [PubMed]

57. Kang, W.; Tang, Y.; Li, W.; Yang, X.; Xue, H.; Yang, Q.; Lee, C.S. High interfacial storage capability of porous $\mathrm{NiMn}_{2} \mathrm{O}_{4} / \mathrm{C}$ hierarchical tremella-like nanostructures as the Lithium-Ion battery anode. Nanoscale 2015, 7, 225-231. [CrossRef]

58. Zeng, Z.; Zhao, H.; Lv, P.; Zhang, Z.; Wang, J.; Xia, Q. Electrochemical properties of iron oxides/carbon nanotubes as anode material for lithium ion batteries. J. Power Sources 2015, 274, 1091-1099. [CrossRef]

59. Zhu, X.J.; Guo, Z.P.; Zhang, P.; Du, G.D.; Zeng, R.; Chen, Z.X.; Li, S.; Liu, H.K. Highly porous reticular tin-cobalt oxide composite thin film anodes for lithium ion batteries. J. Mater. Chem. 2009, 19, 8360-8365. [CrossRef]

60. Fransson, L.; Vaughey, J.; Benedek, R.; Edström, K.; Thomas, J.; Thackeray, M. Phase transitions in lithiated $\mathrm{Cu}_{2} \mathrm{Sb}$ anodes for lithium batteries: An in situ X-ray diffraction study. Electrochem. Commun. 2001, 3, 317-323. [CrossRef]

61. Baggetto, L.; Allcorn, E.; Unocic, R.R.; Manthiram, A.; Veith, G.M. $\mathrm{Mo}_{3} \mathrm{Sb}_{7}$ as a very fast anode material for lithium-ion and sodium-ion batteries. J. Mater. Chem. A 2013, 1, 11163-11169. [CrossRef]

62. Wang, S.; He, M.; Walter, M.; Kravchyk, K.V.; Kovalenko, M.V. Monodisperse CoSb nanocrystals as high-performance anode material for Li-ion batteries. Chem. Commun. 2020, 56, 13872-13875. [CrossRef]

63. Pan, Q.; Wu, Y.; Zhong, W.; Zheng, F.; Li, Y.; Liu, Y.; Hu, J.; Yang, C. Carbon nanosheets encapsulated NiSb nanoparticles as advanced anode materials for Lithium-Ion batteries. Energy Environ. Mater. 2020, 3, 186-191. [CrossRef]

64. Hou, H.; Cao, X.; Yang, Y.; Fang, L.; Pan, C.; Yang, X.; Song, W.; Ji, X. NiSb alloy hollow nanospheres as anode materials for rechargeable lithium ion batteries. Chem. Commun. 2014, 50, 8201-8203. [CrossRef] [PubMed] 
65. Song, G.; Choi, S.; Hwang, C.; Ryu, J.; Song, W.-J.; Song, H.-K.; Park, S. Rational structure design of fast-charging NiSb Bimetal nanosheet anode for Lithium-ion batteries. Energy Fuels 2020, 34, 10211-10217. [CrossRef]

66. Ning, X.; Li, Z. Centrifugally spun SnSb nanoparticle/porous carbon fiber composite as high-performance lithium-ion battery anode. Mater. Lett. 2021, 287, 129298. [CrossRef]

67. Fan, L.; Liu, Y.; Tamirat, A.G.; Wang, Y.; Xia, Y. Synthesis of ZnSb@C microflower composites and their enhanced electrochemical performance for lithium-ion and sodium-ion batteries. New J. Chem. 2017, 41, 13060-13066. [CrossRef]

68. Gómez-Cámer, J.L.; Novák, P. Polyacrylate bound TiSb 2 electrodes for Li-ion batteries. J. Power Sources 2015, $273,174-179$. [CrossRef] 